\title{
BOLETIM DO \\ ARQUIVO DA \\ UNIVERSIDADE \\ DE COIMBRA
}

\section{A importância dos registos de autoridade arquivística nos arquivos de família: o Arquivo Almada e Lencastre Bastos: um caso prático}

\author{
Autor(es): $\quad$ Gago, Alice Borges \\ Publicado por: Imprensa da Universidade de Coimbra \\ URL \\ persistente: URI:http://hdl.handle.net/10316.2/42786 \\ DOI: ～DOI:https://doi.org/10.14195/2182-7974_30_7
}

Accessed : $\quad$ 26-Apr-2023 11:22:11

A navegação consulta e descarregamento dos títulos inseridos nas Bibliotecas Digitais UC Digitalis, UC Pombalina e UC Impactum, pressupõem a aceitação plena e sem reservas dos Termos e Condições de Uso destas Bibliotecas Digitais, disponíveis em https://digitalis.uc.pt/pt-pt/termos.

Conforme exposto nos referidos Termos e Condições de Uso, o descarregamento de títulos de acesso restrito requer uma licença válida de autorização devendo o utilizador aceder ao(s) documento(s) a partir de um endereço de IP da instituição detentora da supramencionada licença.

Ao utilizador é apenas permitido o descarregamento para uso pessoal, pelo que o emprego do(s) título(s) descarregado(s) para outro fim, designadamente comercial, carece de autorização do respetivo autor ou editor da obra.

Na medida em que todas as obras da UC Digitalis se encontram protegidas pelo Código do Direito de Autor e Direitos Conexos e demais legislação aplicável, toda a cópia, parcial ou total, deste documento, nos casos em que é legalmente admitida, deverá conter ou fazer-se acompanhar por este aviso. 


\title{
VOLUME \\ XXXBOLETIM DO \\ ARQUIVO DA \\ UNIVERSIDADE \\ DE COIMBRA
}

\author{
2017 \\ IMPRENSA DA \\ UNIVERSIDADE \\ DE COIMBRA
}

- $\mathrm{U}$

C • 


\section{A importância dos registos de autoridade arquivística nos arquivos de família: o Arquivo Almada e Lencastre Bastos - um caso prático}

\section{The importance of archival authority records in family archives: the Almada e Lencastre Bastos archive - a practical case}

ALICE BORGES GAGO1

Doutoranda na Faculdade de Ciências Sociais e Humanas da Universidade de Lisboa Intituto de Estudos Medievais alicegago@gmail.com

Artigo enviado em: 6 de fevereiro de 2017

Artigo aprovado em: 13 de abril 2017

\section{RESUMO}

Pretende-se com este estudo refletir sobre a importância da descrição arquivística de entidades produtoras, nomeadamente na construção de registos de autoridade arquivística (RAA) de pessoas singulares e famílias, quando se pretende descrever arquivos de família. Esta prática, que tem por objetivo uniformizar e facilitar o acesso aos fundos documentais, é baseada em normas internacionais e nacionais, permitindo a troca de dados entre entidades detentoras de arquivos. A disponibilização de aplicações

1 Bolseira de doutoramento (SFRH/BD/101022/2014) em História, especialidade Arquivística Histórica, na Faculdade de Ciências Sociais e Humanas da Universidade Nova de Lisboa. Membro integrado do Instituto de Estudos Medievais. 
informáticas de descrição arquivística, gratuitas, como o ICA- AtoM, viabilizam não só a descrição, mas também uma maior difusão de fundos documentais, nomeadamente arquivos de família à guarda de entidades privadas ou públicas, como o "Arquivo Almada e Lencastre Bastos".

PALAVRAS-CHAVE: Registos de autoridade; arquivos de família; ICA - AtoM; descrição arquivística.

\section{ABSTRACT}

This study reflects on the importance of people and family archival authority records, in order to provide easier access to the documents. This practice, which aims to standardize and facilitate access to archival funds, is based on several international and national standards, which allow the exchange of data between archival entities. The availability of archival description software, such as ICA-AtoM, enables the description and a greater dissemination of documentary funds, such as family archives deposited at private or public archive services, as in the case of the Almada e Lencastres Bastos family archive.

KEYWORDS: Authority records; family archives; ICA - AtoM; archival description.

\section{Introdução}

A normalização dos instrumentos de descrição arquivística constitui um dos passos fundamentais para a criação de redes de informação de fundos documentais, pelo que vários autores têm vindo a chamar a atenção para a necessidade desta prática desde meados dos anos 90 do século XX. De entre eles podemos referir, a título de exemplo, Richard Cox que afirmou que a existência de normas era um indicador privilegiado do estado de desenvolvimento da disciplina arquivística ${ }^{2}$ ou Carol Couture, que defendeu que a normalização devia ser uma prioridade para o desenvolvimento da arquivística pois ela aumenta a qualidade das intervenções profissionais e melhora significativamente as bases do conhecimento ${ }^{3}$.

O tema dos registos de autoridade tem vindo a ser estudado por vários especialistas ${ }^{4}$ e também no âmbito de estágios e teses de mestrado em

\footnotetext{
2 COX, 1994: 167.

3 COUTURE, 2001: 9.

4 GAGNON-ARGUIN, 1992; RUNA, 2011; LAFUENTE URIÉN, 2014.
} 
Ciências da Informação e da Documentação 5 em universidades portuguesas, que analisaram, sobretudo, a adoção do modelo do Ficheiro Nacional de Autoridades Arquivísticas (FNAA), como modelo a seguir para a criação dos RAA $^{6}$. Como refere Ana Margarida Rodrigues ${ }^{7}$ este modelo apresenta algumas vantagens e é considerado pela entidade gestora, a Direcção-Geral do Livro, dos Arquivos e das Bibliotecas, como o "pilar estruturante da informação disponibilizada na rede"8.

O presente artigo começa por abordar a evolução das políticas de normalização da descrição dos registos de autoridade arquivística e a importância que a criação de normas internacionais tiveram na constituição e implementação de modelos de descrição nas entidades detentoras de arquivos, salientando o contributo do FNAA enquanto entidade agregadora dos RAA das entidades participantes da Rede Portuguesa de Arquivos. De seguida apresentam-se alguns exemplos de preenchimento de RAA do "Arquivo Almada e Lencastre Bastos", depositado na Biblioteca Nacional de Portugal, numa base informática de arquivos, o ICA-AtoM. O preenchimento desta base decorre da investigação que nos encontramos a realizar para a tese de doutoramento em História, especialidade Arquivística Histórica, o que nos levou a analisar alguns constrangimentos inerentes a esse preenchimento e, consequentemente, a gerar políticas de descrição de RAA.

Refletimos ainda sobre o diálogo entre historiadores e arquivistas, e no contributo que os primeiros podem dar na construção de registos de autoridade face à escassez de recursos humanos nas entidades detentoras de arquivos e por fim apresentamos uma sugestão de grelha de preenchimento de RAA em arquivos de família, que poderá servir para trabalhos futuros nesta área.

\section{A normalização da descrição arquivística e criação de registos de autoridade}

A descrição da documentação é, segundo Fernanda Ribeiro, uma das atividades mais importantes na organização de um arquivo, uma vez que,

5 MORAIS, 2013; RODRIGUES, 2013; SILVÉRIO, 2008; TRINDADE, 2012.

6 O FNAA é uma estrutura informática de controlo das autoridades arquivísticas nacionais, por meio do estabelecimento, em ficheiro de autoridade, das formas autorizadas e das formas variantes dos nomes pessoais e de famílias. Mais adiante desenvolveremos o assunto.

7 RODRIGUES, 2013: 10.

8 PORTUGAL, 2008a: 6. 
através dela, se elabora a representação das unidades documentais, permitindo a sua identificação, localização e acesso ${ }^{9}$.

A descrição arquivística normalizada aplica-se não só aos documentos como também às pessoas coletivas, pessoas singulares e famílias enquanto produtoras, acumuladoras ou gestoras de arquivo. Neste processo de normalização das práticas arquivísticas ligadas à descrição é incontornável a presença do Conselho Internacional de Arquivos $(\mathrm{CIA})$, responsável pelo desenvolvimento das quatro normas internacionais de descrição ${ }^{10}$ : a ISAD $(G)^{11}$, a ISAAR(CPF) ${ }^{12}$, a ISDIAH ${ }^{13}$ e a ISDF ${ }^{14}$.

O desenvolvimento de políticas e instrumentos de normalização da descrição arquivística a nível internacional iniciou-se com a criação, em 1989, da Comissão Ad-hoc para as Normas de Descrição do CIA ${ }^{15}$, que deu posteriormente origem ao seu Comité Permanente de Normas de Descrição. No entanto, e como é referido por Bonal Zazo ${ }^{16}$, o trabalho inicial realizado pelo CIA (sobretudo ao nível da norma ISAD(G)) teve como bases teóricas as normas nacionais desenvolvidas nos EUA, Grã-Bretanha e Canadá, durante nos anos 80 do século XX17. A necessidade de criação de normas internacionais, com o fim de orientar, regular e normalizar a atividade de descrição a um nível mais abrangente do que o nacional, surgiu na década seguinte, na sequência de um modo renovado de encarar a descrição arquivística ${ }^{18}$.

Os novos desafios colocados com a proliferação de documentos eletrónicos e com as exigências dos utilizadores, levaram a que a descrição arquivística de variadas entidades, e respetiva normalização, fossem uniformizadas

9 RIBEIRO, 1996: 9.

10 Para uma reflexão e síntese global dos antecedentes de criação, estrutura e objetivos das quatro normas internacionais a seguir elencadas, veja-se: RUNA, 2011: 161-214.

$11 \mathrm{ISAD}(\mathrm{G})$ - General International Standard for Archival Description.

12 ISAAR(CPF) - International Standard Archival Authority Record For Corporate Bodies, Persons and Families.

13 ISDIAH - International Standard for Describing Institutions with Archival Holdings.

14 ISDF - International Standard for Describing Functions.

15 LAFUENTE URIÉN, 2014.

16 BONAL ZAZO, 2001.

17 Refere-se às normas Rules for Archival Description criadas em 1990, e revistas em 2008, ao trabalho de Steven Hensen: Archives, Personal Papers, and Manuscripts: a Cataloging Manual for Archival Repositories, Historical Societies, and Manuscript Libraries (2. ${ }^{a}$ ed., 1989), e ao Manual

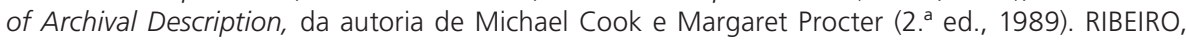
1996: 9; BONAL ZAZO, 2000: 66; GAGNON-ARGUIN, 2012: 109,112.

18 BONAL ZAZO, 2000: 57. 
de forma a facilitar o acesso, recuperação e divulgação da informação, a nível não só nacional, mas também internacional19.

Atualmente, o foco central do trabalho desenvolvido pelo $\mathrm{ClA}$, em termos de normalização da descrição arquivística e da revisão e aperfeiçoamento das quatro normas de descrição já referidas, tem por objetivo a sua reestruturação e otimização da sua articulação e intercomunicação.

Os documentos de trabalho produzidos, em 2012, pelo Committee on Best Practices and Standards 20 do CIA são reveladores desta linha de orientação, ao pretender tornar claras as relações existentes entre os diversos tipos de entidades arquivísticas visados por cada uma delas e apresentar uma reflexão e propostas de harmonização dos elementos de informação contemplados em cada uma das normas internacionais, a fim de diminuir a repetição de informação e aumentar a sua articulação. Nesse mesmo ano, o CIA constituiu um novo grupo de trabalho, o EGAD (Experts Group on Archival Description), com o objetivo de desenvolver um modelo conceptual internacional que proporcionasse uma base mais sólida à descrição arquivística, adequando-a aos desafios da nova geração de sistemas de descrição (no contexto da web semântica, centrada na articulação de dados estruturados) e de partilha de informação a nível internacional e interdisciplinar (articulação com a comunidade museológica e biblioteconómica) ${ }^{21}$.

É neste quadro de uniformização e normalização da descrição arquivística, que foram criadas, a partir dos anos 90 , as normas para os registos e controlo de autoridade e sua aplicação à realidade arquivística, a ISAAR(CPF)22, que teve a sua primeira edição em 1996 e a segunda edição (revista) em 200423. Desde então, tem sido progressivamente utilizada como fonte, quer para a criação direta de RAA para pessoas coletivas, singulares e famílias, quer para a elaboração de normas a nível nacional e internacional.

19 RUNA, 2011: 164; GUEDES, 2015

20 INTERNATIONAL COUNCIL ON ARCHIVES. Committee on Best Practices and Standards. Sub-committee on archival description - Relationships in archival descriptive systems. [Consult. 23 Out. 2016]. Disponível em: <http://www.ica.org/sites/default/files/Relationships_archival_descriptive_standards.pdf>; id., Progress report for revising and harmonising ICA descriptive standards. [Consult. 23 Out. 2016]. Disponível em: <http://www.ica.org/sites/default/files/Report_for_revising_harmonising_description_standards.pdf>; LAFUENTE URIÉN, 2014.

21 O grupo disponibilizou uma versão rascunho da primeira parte do documento em INTERNATIONAL COUNCIL ON ARCHIVES. Experts Group on Archival Description - Records in contexts: a conceptual model for archival description. Consultation Draft v 0.1. ICA, September 2016. [Consult. 8 Mar. 2017]. Disponível em: <http://www.ica.org/en/egad-ric-conceptual-model>.

22 CONSELHO INTERNACIONAL DE ARQUIVOS, 2004: 6.

23 Id. 
Ainda antes da publicação da ISAAR(CPF) já Cynthia J. Durance 24 havia enunciado os benefícios do controlo de autoridades 25 ao nível da uniformização e recuperação da informação arquivística e, consequentemente, no acesso à documentação. Estes benefícios eram potenciados quando a informação normalizada era inserida em ambiente electrónico, o que permitia o cruzamento da informação, identificava e descrevia os tipos de autoridades arquivísticas 26 , o modo como se interrelacionavam, referindo os benefícios da sua utilização normalizada e os requisitos básicos necessários para que o controlo de autoridades fosse criado e implementado numa instituição.

Pouco tempo depois da publicação da versão inicial da ISAAR(CPF), Sharon Thibodeau apresentou uma primeira reflexão acerca desta norma no artigo "Archival Context as Archival Authority Record: the ISAAR(CPF)"27, onde chamou a atenção para a utilização de pontos de acesso normalizados associados à descrição documental, e para a proposta de utilização de registos de autoridade (tradicionalmente existentes e regulados para o universo biblioteconómico) e para as necessidades específicas da descrição arquivística ${ }^{28}$. Referiu ainda o reconhecimento internacional da importância dos registos de autoridade na recuperação da informação arquivística, aliado ao peso crescente do paradigma pós-custodial29, que havia impulsionado, desde o início da década de 90, o trabalho da comissão responsável pela elaboração da ISAAR(CFP).

A ISAAR(CPF) tem sido, e provavelmente até mais do que ISAD(G), um verdadeiro ponto de viragem na teoria e na prática de descrição arquivística, constituindo uma ferramenta através da qual se podem superar algumas dúvidas teóricas da arquivística que tem sido pensadas e discutidas nas últimas décadas do século XX em alguns contextos nacionais 30 .

No que se refere a Portugal, a partir dos anos 90, começou a desenvolver-se alguma reflexão teórica sobre os arquivos de família no, então, Instituto Português de Arquivos, versando sobretudo os problemas de orga-

\footnotetext{
24 DURANCE, 1993: 38-46.

25 Ib.: 38.

26 "... corporate names, their histories and functions (including names of government organizations, families and corporations); personal names (individuals) and biographical details about them; subjects (including names used as subjects and geographic names) and functions, occupations and/or forms of material". Ib.: 40.

27 THIBODEAU, 1995: 75-85.

28 Ib.: 76.

29 COOK, 1993: 24-37.

30 Ver, a título de exemplo, o caso italiano apresentado em VITALI, 2004: 187.
} 
nização e descrição dos acervos. Nesta linha, a Associação Portuguesa de Bibliotecários, Arquivistas e Documentalistas (BAD) criou um grupo de trabalho sobre os arquivos de família, que privilegiava os mesmos temas ${ }^{31}$. Por seu lado, Pedro Abreu Peixoto, publicou um pequeno estudo onde defendia a extensão de uma "política de arquivos" para este sector, também no quadro de afirmação da identidade arquivística que então se vivia (rede nacional de arquivos, políticas de arquivos, produção de instrumentos de descrição à escala nacional, discussão sobre a configuração do arquivo nacional, etc.) 32. O mesmo autor havia publicado, em 1999, um outro artigo onde, na falta da ISAAR(CPF), tinha adaptado a utilização da ISAD(G) aos arquivos de família, embora com inúmeras limitações (nomeadamente a nível da zona de relacionamento, então inexistente) ${ }^{33}$. Anos mais tarde, Lucília Runa e Joana Braga de Sousa34 levantaram questões relativas às dificuldades e desafios existentes na normalização da descrição e ao modo de as ultrapassar. As autoras refletiram sobre a importância da normalização da descrição das entidades produtoras como forma de melhorar a gestão documental, potenciar a partilha de informação entre arquivos nacionais e internacionais e aumentar a eficácia dos instrumentos de recuperação de informação ao dispor dos utilizadores dos arquivos.

Em 2007, o grupo de trabalho dos arquivos municipais, da BAD, chamou a atenção sobre fundos documentais que englobam os arquivos de família num encontro anual que versou o tema Fundos Privados em Arquivos Municipais: Perspectivas e Projectos, cujas atas podem ser consultadas em linha. De entre as várias conclusões do encontro, foi recomendado que os arquivos municipais tratassem e difundissem os arquivos privados à sua guarda como também estabelecessem parcerias com famílias detentoras de arquivos 35 .

Em Portugal, o Grupo de Trabalho para a Normalização da Descrição em Arquivo tem vindo a coordenar os processos de tradução e disponibilização das normas de descrição internacionais, desempenhando assim um importante papel na divulgação da importância da sua aplicação. Nessa linha

31 Este grupo de trabalho encontra-se inativo há alguns anos.

32 PEIXOTO, 1994: 43-48.

33 Nomeadamente para a descrição das relações entre produtores e/ou acumuladores. PEIXOTO, 1999: 55-70; RUNA e SOUSA, 2003: 100.

34 RUNA E SOUSA, 2003: 80-108.

35 ENCONTRO NACIONAL DE ARQUIVOS MUNICIPAIS, 8, Vila Real, 2007 - Conclusões. [Consult. 8 Mar. 2017] Disponível em: <http://www.apbad.pt/Downloads/GT_Downloads/ Conclusoes_8EncontroArqMun.pdf>. 
foram criadas as Orientações para a Descrição Arquivística (ODA) ${ }^{36}$, que contemplam uma parte dedicada à descrição de autoridades arquivísticas e demonstrando que, sobretudo a partir do final da década de 90 do século $X X$, a normalização da descrição em arquivo tem vindo a ser considerada como crucial pelo órgão de coordenação da política arquivística nacional. Tanto a disponibilização da tradução em português das normas de descrição, como a elaboração das ODA têm vindo a ser acompanhadas por reflexões sobre a sua importância e sobre os desafios e as possibilidades da sua utilização, sobretudo em contexto tecnológico.

Lucília Runa ${ }^{37}$, num texto de 2007 sobre as ODA, reflete sobre os seus objetivos e benefícios, e remete para um modelo da sua aplicação em alguns projetos, já então em curso, como a Rede Portuguesa de Arquivos (RPA) e o Ficheiro Nacional de Autoridades Arquivísticas e consequente normalização e utilização da descrição de autoridades arquivísticas. Destaca ainda os benefícios de uniformização da informação trazidos pelas normas de descrição acima referidas, sobretudo no que respeita à sua partilha a nível internacional, que são potenciadas quando aplicadas em contexto eletrónico de bases de dados interativas e quando lhe é dada a possibilidade de projeção no universo digital do cruzamento de informação na rede.

Paralelamente, em Espanha foi também criada uma comissão para a descrição arquivística, a CNEDA, Comisión de Normas Españolas de Descripción Archivística, que, em 2012, produziu o Modelo Conceptual de Descripción Archivistica y Requisitos de Datos Básicos de las Descripciones de Documentos de Archivo, Agentes y Funciones ${ }^{38}$, com vista à constituição das NEDA Normas españolas de descripción archivística.

Antonia Heredia Herrera definiu num breve parágrafo a essência deste modelo conceptual:

“El nuevo modelo conceptual se aparta de una descripción plana y rígida, como era la practicada para elaborar instrumentos de descripción, y la llena de relieve al potenciar con las relaciones, la descripción de los contextos documentales. [...] En definitiva, y esto es bien significativo: de los instrumentos de descripción hemos pasado a un sistema de descripción archivística, que representa la gran evolución del modelo estático a partir de una descripción plana, unidimensional, a un modelo pluridimensional, con una descripción con muchas

\footnotetext{
36 PORTUGAL, 2011.

37 RUNA, 2007.

38 ESPANHA, 2012.
} 
dimensiones, y lo que es más extraordinario no exige la formación previa de los usuarios"39.

Em França procedem-se também a trabalhos de adaptação de normas nacionais, mas sem texto ainda definido 40 .

Mais recentemente surgiram as Encoded Archival Context for Corporate Bodies, Persons and Families (EAC (CPF)), no contexto da difusão da informação na rede, de forma a facilitar a troca de dados, baseados numa linguagem XML, cuja última versão de 2010 tem sido acompanhada pelo desenvolvimento de modelos conceptuais, ontologias e sistemas Linked Open Data (LOD) ${ }^{41}$. O foco tem sido, tal como a ISAAR (CPF) dado à área das relações entre criadores e outras fontes de informação (museus, bibliotecas e outros recursos), tornando as duas normas complementares.

\section{Ficheiro Nacional de Autoridades Arquivísticas}

Ao contrário da tradição biblioteconómica, que sistematicamente assumiu a necessidade e vantagem da criação, gestão e disponibilização de registos de autoridade independentes, integrados em ficheiros de autoridades bibliográficas, agregados numa única plataforma a partir da qual é permitida a sua difusão42, as práticas nacionais no domínio da arquivística só presentemente começaram a romper com a tradicional descrição de entidades. Estas têm sido baseadas no aproveitamento da descrição arquivística do arquivo, incluindo informação relacionada com a sua proveniência, isto é, sobre a entidade produtora e o contexto de produção. Embora a tradição ainda se mantenha, em detrimento da criação e gestão de RAA em separado, salienta-se que a descrição das autoridades arquivísticas em conjunto com a descrição documental já foi questionada e assumida como insuficiente e desvantajosa pela entidade coordenadora das políticas arquivísticas nacionais 43 .

39 HEREDIA HERRERA, 2010: 167.

40 ARCHIVISTES - [Em linha]. [Consult. 23 Out. 2016]. Disponível em: <http://www.archivistes.org/Notices-d-autorite-producteurs-1781>.

41 LAFUENTE URIÉN, 2014.

42 Já Louise Gagnon-Arguin havia chamado a atenção para a necessidade da criação de registos de autoridade para as entidades produtoras de arquivos, tal como a biblioteconomia havia criado registos de autoridade bibliográficos. GAGNON-ARGUIN: 1992, 10-13; LAFUENTE URIÉN, 2014.

43 PORTUGAL, 2011: 211. 
Nessa linha de rutura foi criado o Ficheiro Nacional de Autoridades Arquivísticas que constitui uma estrutura de informação informática com o propósito de gerir diversas entidades previstas na Rede Portuguesa de Arquivos $(\mathrm{RPA})^{44}$, cuja gestão se encontra a cargo do órgão de coordenação da política arquivística (atualmente a Direcção-Geral do Livro, dos Arquivos e das Bibliotecas), com o objetivo de controlar as autoridades arquivísticas nacionais, por via da fixação, em ficheiro de autoridade, das formas autorizadas e das formas variantes dos nomes pessoais e de famílias, constituindo pontos de acesso aos registos, e como tal, recuperáveis e relacionáveis numa pesquisa de informação. Esta última, enquanto rede agregadora e difusora de informação arquivística contempla também o Portal Português de Arquivos (PPA) 45 , onde se encontram depositadas os dados provenientes de vários arquivos portugueses com os quais estabeleceram protocolo de cooperação. Assim, a nível nacional, a partilha da informação é efetuada através do FNAA e do PPA, o qual, em articulação com o Portal Europeu de Arquivos46, permite a disponibilização dos conteúdos do PPA a nível internacional.

O órgão coordenador é responsável pela definição e normalização de critérios para a elaboração dos RAA, testa, avalia e controla a qualidade dos conteúdos, a pertinência e a coerência das ligações estabelecidas entre os RAA, entre estes e a documentação de arquivo e os outros recursos, entre os RAA e a descrição das funções 47 , e decide inclusivamente, acerca da sua disponibilização ou não disponibilização no ficheiro.

O FNAA permite o acesso simultâneo a "diversas áreas informacionais relativas a produtores, detentores, funções, registos patrimoniais, relacionadas de uma forma coerente" 48 , a partir de um único ponto, através dos registos de autoridade. Tal torna-se possível devido à sua organização por módulos, tais como: entidades produtoras e detentoras, entidades aderentes à RPA, funções, registos patrimoniais de classificação, recursos externos e relações internas e externas que podem ser estabelecidas entre as entidades presentes no FNAA e entre estas e outros recursos (arquivísticos, biblioteconómicos, museológicos, entre outros).

44 PORTUGAL, 2008b e 2008c e PORTUGAL. Direcção-Geral do Livro, dos Arquivos e das Bibliotecas - Rede Portuguesa de Arquivos [Em linha]. Disponível em: <http://arquivos.pt>.

45 Veja-se PORTUGAL. Direcção-Geral do Livro, dos Arquivos e das Bibliotecas - Portal Português de Arquivos [Em linha]. Disponível em: <http://portal.arquivos.pt>.

46 ARCHIVES PORTAL EUROPE - [Em linha]. [Consult. 23 Out. 2016]. Disponível em: <http:// www.archivesportaleurope.net/home>.

47 PORTUGAL, 2008a: 15.

48 PORTUGAL, 2008a: 4. 
O FNAA tem como objetivos gerais

"descrever, de forma normalizada e autónoma, as autoridades arquivísticas, [...] permitir a partilha e a troca de informação, a nível nacional e internacional, rentabilizando trabalho e recursos, criar e controlar a criação de pontos de acesso normalizados à documentação de arquivo e estabelecer a sua equivalência com pontos de acesso criados com base em diferentes tipos de normas, que podem transcender as arquivísticas (biblioteconómicas, ou museológicas), [...] documentar as relações entre elas e a documentação de arquivo com a qual se relacionam ou com outros recursos informativos com os quais se relacionem, nomeadamente bibliográficos, arqueológicos, etnológicos, espécies artísticas, etnográficas, outros bens móveis e imóveis, classificados ou não e ainda tornar acessível às organizações produtoras e detentoras de documentação de arquivo, um repositório de identificadores unívocos e persistentes, bem como as respetivas formas autorizadas dos nomes"49.

Enquanto plataforma de armazenamento, cruzamento e dinamização de informação, o FNAA proporciona uma experiência interativa ao seu utilizador, os quais podem pesquisar e consultar os RAA que o integram, navegar entre os RAA utilizando as ligações estabelecidas entre eles, entre muitas outras funcionalidades 50 . Os utilizadores registados podem ainda propor novos RAA a integrar no FNAA ou a revisão e atualização de RAA já existentes. Importa, no entanto, salientar que, atualmente, o FNAA está a ser alimentado apenas com RAA de entidades produtoras de arquivos que cumpram um conjunto de requisitos pré-estabelecidos 51 .

A utilização do FNAA pode possibilitar a compreensão do contexto de produção e utilização dos documentos de arquivo; permitir a recuperação da informação pertinente através do contexto de produção dos documentos, facilitar a pesquisa de informação, melhorar a gestão documental nas organizações fornecendo dados normalizados para registo de produtores, colecionadores, autores, detentores de documentos de arquivo e constituir um ficheiro de referência para o conjunto de entidades produtoras, detentoras, colecionadoras ou com qualquer tipo de relação com a documentação de arquivo, permitindo a sua identificação unívoca52.

\footnotetext{
49 Ib.: 4-5.

50 Para mais especificações técnicas, ver LEROUX, 2012.

51 PORTUGAL, 2008a: 8-9.

52 PORTUGAL, 2008a: 4-5.
} 


\section{A importância da criação de normas para a descrição de autoridades arquivísticas}

Sendo os arquivos um produto de uma família, uma pessoa ou uma instituição, a natureza destas entidades individuais ou corporativas, os seus acontecimentos históricos e biográficos são uma base fundamental para compreender e avaliar os documentos conservados nos arquivos que criaram $^{53}$. Nessa perspetiva, descrever arquivos significa, acima de tudo, fornecer informações sobre os seus produtores e sobre o contexto histórico da criação do arquivo.

Até ao aparecimento das ISAAR(CPF), os arquivos eram alvo de uma abordagem tradicional, que considerava a relação entre fundos documentais e produtores como linear, mono-dimensional e estática, em que o produtor estava ligado a um único fundo arquivístico e, inversamente, cada fundo arquivístico compreendia os documentos de um só produtor. Este tipo de abordagem teve algumas consequências de ordem prática: quando, na presença de arquivos que não se encaixavam neste modelo de correspondência entre fundos e produtores, foram criadas ligações onde as não havia, ou seja, fundos diferentes criados por um mesmo produtor, foram unificados em fundos maiores, ou a situação inversa: fundos constituídos por documentos de vários produtores foram separados.

Mais recentemente, os arquivistas tornaram-se mais conscientes da inadequação do modelo de relação linear entre arquivos e produtores, da complexidade da estrutura, funções e sistemas de manutenção dos arquivos, assim como compreenderam de uma forma mais clara os processos de transmissão de materiais de arquivo nos séculos passados. Esses processos, numa análise mais aprofundada, provaram ser menos lineares do que a arquivística tinha afirmado e previsto ${ }^{54}$. Quando representamos as relações que ocorrem entre os arquivos e seus produtores, devemos construir um modelo que preveja a possibilidade de que mais do que um produtor possa estar ligado a um arquivo e, inversamente, que mais do que um fundo arquivístico possa estar ligado a um produtor. O resultado é um modelo que prevê uma relação dinâmica multidimensional e multilinear, numa perspetiva diacrónica.

Um dos méritos principais da ISAAR (CPF) e o que mais influenciou não só as formas de organização da descrição arquivística, mas a própria forma

\footnotetext{
53 VITALI, 2004: 187-188

54 Ib.: 188-189.
} 
de avaliar arquivos foi o facto de que ela ofereceu um modelo capaz de representar de forma mais eficaz a relação complexa e multidimensional entre fundos documentais e produtores, descrevendo separadamente, mas em associação, produtores e arquivos. Desta forma, os produtores são descritos autonomamente, relacionados com a documentação que realmente produziram, independentemente da instituição onde está a documentação, o que significa, por um lado, trazer praticamente de volta para uma unidade todo o arquivo produzido por um determinado produtor; por outro lado, respeita os modos de organização e transmissão de documentos, que são sempre ricos em significados e suas múltiplas implicações. Fundar a descrição arquivística neste modelo implica o reconhecimento da possibilidade e da oportunidade de partilhar as descrições de entidades entre as entidades detentoras de arquivos (mas também bibliotecas e museus), que podem ter documentos criados pelo mesmo produtor. Estes objetivos encontram-se enunciados na introdução à nova edição da ISAAR(CPF), e recordam conceitos já expressos na primeira edição55.

De uma maneira geral, a norma prevê a elaboração de registos com diferentes níveis de detalhe, o que constitui, pelo seu grau de exigência, um desafio para os arquivistas, que devem definir o nível de profundidade (mínimo a máximo) das descrições a produzir, o perfil da informação a registar em cada campo, as relações a criar entre as descrições dos vários produtores (pessoas coletivas, singulares e famílias) e os recursos arquivísticos: relações de produção e/ou acumulação56.

As alterações mais significativas entre as duas versões da ISAAR (CPF) verificaram-se sobretudo na zona de relacionamento. Enquanto que na primeira versão as relações entre entradas de autoridade, eram feitas por "ver" e "ver também", na segunda edição, foi criada uma área cuja finalidade é apresentar as relações de um determinado produtor com outro apontando para: nome e identificador da entidade relacionada; categoria da relação (hierárquica, cronológica, familiar); natureza específica da relação e sua descrição; datas de relacionamento. Esta atenção às relações entre diferentes entidades, e a implementação de sistemas que não estão limitados à gestão do relacionamento entre produtores e que pode representar as ligações complexas existentes entre os vários produtores, pode ser importante para um investigador obter informações sobre os percursos de uma família

55 Enunciadas nos pontos 1.5 e 1.6. CONSELHO INTERNACIONAL DE ARQUIVOS - ISAAR (CPF): 9.

56 RUNA, 2011: 171. 
ou pessoa singular dentro dos arquivos ou dos documentos produzidos por diversos produtores 57 .

As ferramentas para o controle de autoridade de produtores parece a melhor forma para a realização de tal objetivo de ligação. Da mesma forma pela qual os produtores estão ligados às descrições dos documentos de arquivo, os registos de autoridade de pessoas, famílias e instituições podem ser facilmente ligados a recursos de informação relacionados com eles e pode ser encontrada em bases de dados que não de arquivo ou outras bases acessíveis através da Internet, como sítios web. Assim, incentiva-se a ligação de sistemas de arquivo para outros recursos na Internet, de modo a permitir, por exemplo, encontrar, por meio do mesmo registo de autoridade de uma determinada pessoa, o registo descritivo de um fundo criado por ele, os registos do catálogo dos livros de sua autoria, mas também, se presente em formato digital, os seus textos e assim por diante. Tomemos por exemplo o caso de Francisco de Almada e Mendonça (1720?-1783), primeiro Visconde de Vila Nova de Souto del Rei, um dos produtores do ALB, cujo registo de autoridade no FNAA permite recuperar a documentação produzida pelo mesmo existente na Torre do Tombo (vários fundos, como "Armário Jesuítico e Cartório dos Jesuítas", "Ministério dos Negócios Estrangeiros") ou outros arquivos integrados na RPA58. O FNAA poderia recuperar ainda informação em outras entidades detentoras de documentação, como por exemplo no arquivo documental do Museu Nacional dos Coches 59 , ou ainda na Biblioteca Nacional de Portugal, no ALB que nos encontramos a estudar, assim estas possam reunir as condições definidas no FNAA para a sua inclusão60. Este modelo, que poderemos considerar orgânico-funcional, tem sido defendido em Portugal por vários arquivistas, dos quais destacamos, por ser o seu principal teórico, Armando Malheiro da Silva61.

O objetivo genérico da segunda edição da ISAAR(CPF) é fornecer regras gerais para a normalização de descrições arquivísticas, não só dos produtores de arquivo mas também do contexto da produção documental. A gestão da informação contextual deve ser independente da descrição documental,

57 VITALI, 2004: 193; LAFUENTE URIÉN, 2014.

58 Não pudemos confirmar dados por o servidor não estar operacional.

59 Gravura do cortejo da embaixada de D. José ao Papa Pio VI pelo Embaixador Visconde de Vila Nova do Souto de El-Rei, em 1775. [Consult. 11 mar. 2017]. Disponível em: <http://www. matriznet.dgpc.pt/MatrizNet/Objectos/ObjectosConsultar.aspx?ldReg=147869.

60 PORTUGAL, 2008a: 8-9.

61 SILVA et alii, 2002; SILVA, 1997: 51-106; id., 2004: 55-84. 
por permitir ligar a descrição de um mesmo produtor a diferentes descrições da documentação, o que possibilita a melhoria da gestão de documentos e potencia a pesquisa e a troca de informação contextual sobre um produtor entre os serviços de arquivo, quer nacional, quer internacionalmente e ainda a partilha de descrições de produtores, garantindo a redação de descrições compatíveis, pertinentes e explícitas 62 .

De certa forma, as normas acabam por estabelecer um paralelismo entre o registo de autoridade arquivística e o registo de autoridade bibliográfica: têm o objetivo comum de criar pontos de acesso normalizados às entidades descritas e ambos utilizam qualificativos unívocos das respetivas entidades produtoras. A diferença reside no facto de as autoridades arquivísticas revelarem exigências suplementares de informação sobre o contexto de produção da documentação.

A constituição de RAA tem as seguintes vantagens:

- identifica univocamente cada uma das famílias ou pessoas singulares63, enquanto autoridades arquivísticas produtoras de fundos documentais, incorporando e descrevendo relações entre elas (suas evoluções e alterações) e agilizando o acesso aos fundos documentais;

- controla a criação e a utilização de pontos de acesso;

- permite o acesso aos arquivos a partir da descrição do seu contexto de produção, estando esta associada à descrição dos documentos, mesmo que dispersos, o que possibilita uma melhor compreensão por parte dos utilizadores quer desse mesmo contexto de produção, quer dos usos dos documentos de arquivo;

- partilha as descrições entre entidades detentoras de fundos documentais, sistemas e redes arquivísticas;

- permite a caracterização e descrição das ligações do registo de autoridade arquivística dos produtores não só à documentação de arquivo como a outros recursos, funcionando como instrumento de referência: instrumentos de descrição documental, monografias, artigos de jornal, fotografias, coleções museológicas, só para citar alguns ${ }^{64}$.

\footnotetext{
62 RUNA e SOUSA, 2003: 96; RUNA, 2011: 169.

63 A identificação unívoca e detalhada já havia sido identificada por ROE, 1993: 119-129.

64 Id., p. 102; RUNA e SOUSA, 2003: 97.
} 


\section{Preenchimento de RAA em arquivos de família: o Arquivo Almada e Lencastre Bastos - uma experiência em ICA-AtoM}

A investigação histórica sobre as Épocas Medieval e Moderna tem sido enriquecida pela revalorização dos arquivos de família, quer pelos contributos de criação de biografias, prosopografias, estudos sobre as diversas formas de organização do parentesco, quer pela informação produzida pelas próprias famílias que permite estudar a forma com este corpo social se auto-organizava, autoidentificava, autorreproduzia e autossustentava65. O estudo dos seus arquivos permite medir o papel da gestão documental na estruturação e manutenção do corpo linhagístico e de uma maneira geral, pode dizer-se, em certos aspetos, que o uso desta documentação permite a entrada na História de pessoas pouco estudadas ou até mesmo desconhecidas, o que possibilita o "questionamento de versões do processo histórico construídas, sobretudo ou apenas, a partir dos acervos dos corpos sociais mais "administralizados" e/ou mais representados nos arquivos do Estado nação"66. Verifica-se uma inexistência quase total dos arquivos de família nos fundos documentais disponíveis nos arquivos públicos, ou então, quando existem são marcados por descrições insuficientes ou inadequadas, ou pouco difundidas.

Esta temática tem vindo a estar na base, quer de mestrados em Ciências da Informação e da Documentação - Ramo Arquivística, quer do curso de doutoramento em Arquivística Histórica da Faculdade de Ciências Sociais e Humanas - Universidade Nova de Lisboa, onde o estudo orgânico-funcional de arquivos de família tem permitido a elaboração de RAA dos vários elementos de uma família. Para tal, os alunos têm procurado preencher os RAA numa base de dados, ICA-AtoM, disponibilizada no servidor da Faculdade.

O ICA-AtoM (acrónimo de "Access to Memory") é uma aplicação informática de descrição arquivística, que permite a descrição normalizada de autoridades arquivísticas, permitindo às entidades detentoras de arquivos que o utilizam criar o seu próprio ficheiro de autoridades e foi desenvolvida de raiz para utilizar e articular entre si as normas de descrição do CIA67.

O seu desenvolvimento, apoiado pela UNESCO e sob a supervisão do $\mathrm{CIA}$, remonta a 2003 , tendo a sua primeira versão sido disponibilizada em 2009. Trata-se de um software de código de fonte aberto, cujo objetivo é dar a possibilidade a arquivos de menores dimensões (por exemplo, arquivos

\footnotetext{
65 ROSA, 2009: 36.

66 Ib.: 37 e bibliografia citada na nota 90.

67 ISAD(G), ISAAR(CPF), ISDIAH e ISDF.
} 
familiares) de terem os seus conteúdos disponíveis em linha, numa plataforma que permite o cruzamento dos dados e a partilha da informação68.

Todas as descrições arquivísticas feitas através desta aplicação estão de acordo com as normas internacionais de descrição. O ICA-AtoM dispõe de uma plataforma, onde cada pessoa ou instituição registada pode criar entidades detentoras, registos de autoridade, descrições arquivísticas, funções, assuntos, locais, objetos digitais. Esta aplicação, para além de fornecer automaticamente os elementos de informação a preencher para cada um dos tipos de descrição, cruza os dados existentes e fornece informações interativas aos utilizadores que efetuam pesquisa em linha. Para além disso, tem a capacidade de importar registos de outros repositórios e de congregar, num só portal, informações de diferentes repositórios ${ }^{69}$. O facto de ser uma aplicação que contempla a criação normalizada de registos de autoridade, permite a quem a utiliza ficar habilitado a criar e a disponibilizar os seus próprios ficheiros de autoridade 70 .

O ICA-AtoM adapta-se por completo ao novo modelo conceptual de descrição arquivística que as normas ISAD (G), ISAAR (CPF), ISDF e ISDIAH hoje exigem ${ }^{71}$. A sua estrutura responde a todas as entidades principais ou classes de "objetos" sobre as quais se recolhe informação: documentos de arquivo, agentes, funções, entidades detentoras de arquivos, temas e lugares. Neste novo modelo cada uma das entidades poderá ser descrita mediante representações independentes mas relacionadas umas com outras, dentro de um sistema informático que evita a repetição, melhora a investigação e a recuperação da informação. Desta forma, o ICA-AtoM não só é uma ferramenta flexível, mas também uma ajuda na descrição dos RAA ou dos documentos 72 .

São vários os exemplos de utilização desta aplicação a nível internacional, como por exemplo na descrição do acervo fotográfico do arquivo Histórico Municipal de Santa Maria, em Rio Grande do Sul (Brasil)73, Faculdade de

68 Os objetivos do projeto ICA-AtoM encontram-se enumerados em BUSHEY, 2012 e em VAN GARDEREN, 2009.

69 INTERNATIONAL COUNCIL ON ARCHIVES - ICA-AtoM. Open source archival description software. [Em linha]. [23 Out. 2016]. Disponível em: <www.ica-atom.org>. Este website fornece todas as informações relativas ao ICA-AtoM, às suas funcionalidades, funcionamento e bases conceptuais.

70 Sobre a avaliação do programa ver: SIMÕES, 2010.

71 Recentemente este modelo conceptual começou a ser questionado pelo próprio ICA, apresentando uma proposta da sua revisão e substituição, embora ainda registe algumas fragilidades. INTERNATIONAL COUNCIL ON ARCHIVES, 2016: 8.

72 MARQUES, 2013: 29; VENTURA, 2011: 94-101; ARAÑA CRUZ e HERRERA TEJADA, 2001: 5-6.

73 HEDLUND E FLORES, 2014: 24-41. 
Direito "Clóvis Bevilaqua" (1959-1972), da Universidade Federal do Rio Grande - FURG74, no Archivo del Ateneo de Madrid75, entre tantos outros.

Em Portugal, a sua utilização foi adotada por vários projetos de investigação, como o INVENT.ARQ76, ou mesmo em arquivos, como o Centro de Arquivo e Documentação da CGTP-IN77, o Arquivo da Social Democracia78, o arquivo da Câmara Municipal de Albufeira ${ }^{79}$, só para citar alguns casos. O crescente número de entidades detentoras de arquivo que se encontram a utilizar esta aplicação levou a que se tenha já organizado um encontro, que juntou utilizadores, arquivistas, informáticos, pelo grupo de trabalho AtoM da Rede de Arquivos do Algarve, onde foram partilhadas experiências e trocas de saberes 80 .

No que se refere à utilização do ICA-AtoM como base de dados arquivística de suporte à elaboração de teses, quer de mestrado ou de doutoramento de Ciência da Informação ${ }^{81}$ como em Arquivística Histórica, tem sido utilizado por vários mestrandos e doutorandos com trabalhos sobre arquivos de família, alguns já concluídos e outros ainda em curso, dos quais destacamos o da Casa de Calheiros82, Castro/Nova Goa83, Casa de Santa Iria84, assim como o dos Condes de Belmonte ${ }^{85}$ e Gama Lobo Salema ${ }^{86}$. É ainda nesta base ${ }^{87}$ que estão ser descritos os documentos e RAA de família e pessoas singulares do Arquivo Almada Lencastre Bastos, à guarda da Biblioteca Nacional de Portugal desde 1974, de que se apresentam dois exemplos em anexo no final deste artigo, e que constituirá uma parte da análise orgânico-funcional

\footnotetext{
74 SANTOS E FLORES, 2012.

75 ARAÑA CRUZ e HERRERA TEJADA, 2001

76 Projeto INVENT.ARQ. [Em linha]. [Consult. 23 out. 2016]. Disponível em: <http://www. inventarq.fcsh.unl.pt/index.php/?sf_culture=pt $>$.

77 PORTUGAL. Confederação Geral dos Trabalhadores Portugueses - Intersindical Nacional - Centro de Arquivo e Documentação. [Em linha]. Disponível em: <http://cad.cgtp.pt/>.

78 PORTUGAL. Partido Social Democrata - Arquivo da Social Democracia. [Em linha]. Disponível em: <http://fotos.psd.pt/atom/index.php/psd-partido-social-democrata-2>.

79 PORTUGAL. Câmara Municipal de Albufeira - Arquivo Municipal. [Em linha]. Disponível em: <http://arquivo.cm-albufeira.pt/>.

80 GRUPO DE TRABALHO ATOM DA REDE DE ARQUIVOS DO ALGARVE, 2016.

81 MORAIS, 2013

82 VENTURA, 2011.

83 MARQUES, 2013.

84 LEME, 2012: 479-490.

85 SOUSA, 2012: 491-506.

86 NÓVOA, 2012: 507-521; 2016

87 http://www.arquivisticahistorica.fcsh.unl.pt/index.php/
} 
do arquivo com vista à elaboração da nossa tese de doutoramento. Neste momento procede-se ainda à identificação das famílias envolvidas e seus elementos, tendo sido até ao momento preenchidos cerca de trinta RAA.

Para a elaboração destes registos foi necessário recorrer a diversa bibliografia, nomeadamente o de Pedro Pinto, publicado no volume de comunicações do Colóquio Internacional Arquivos de Família, séculos XIII-XX: Que presente, que futuro? ${ }^{88}$, onde fez um pequeno estudo introdutório sobre o arquivo e algumas famílias nele representadas. A partir dessa bibliografia, fomos aferindo os dados com outras obras, como a de Francisco de La Fuente 89 sobre D. Miguel Pereira Forjaz ou ainda genealogias como a de Fernando Canedo90. Esta última apresenta, no entanto, algumas imprecisões ${ }^{91}$.

Para a criação destes registos de autoridade também contribuiu, como não podia deixar de ser, a consulta do próprio arquivo. No já referido trabalho de Pedro Pinto, o autor iniciou a construção de um catálogo dos maços/ caixas do arquivo, o qual nos encontramos a completar e que nos permitiu ir recolhendo mais informações, nomeadamente de elementos familiares que foram aparecendo nos documentos do arquivo, assim como dados biográficos mais precisos, de carreiras militares e diplomáticas e que nos ajudou a elaborar um esquema de sistemas familiares que irão ser introduzidos na base de dados. De referir ainda a consulta dos vários inventários existentes no arquivo, quer da parte da família Almada e Lencastre, mandados fazer pelo último visconde em meados do século XIX, quer da parte dos Pereira Forjaz Coutinho, mais ou menos da mesma época.

Assim, no que se refere ao preenchimento da base de dados ICA-AtoM, para além da entidade detentora, Biblioteca Nacional de Portugal, com informação recolhida do site institucional, o RAA do fundo/sistema Arquivo Almada e Lencastre Bastos foi alterado com a chegada de novos dados 92 . A história custodial começou a ser preenchida com dados concretos a partir da consulta do processo de aquisição do arquivo existente na Torre do Tombo93. Falta ainda conferir mais alguns elementos, que pensamos poder

\footnotetext{
88 PINTO, 2012: 307-341.

89 FUENTE, 2011.

90 CANEDO, 1993.

91 A título de exemplo poderemos referir a data de falecimento de D. António Almada e
} Lencastre, $4 .^{\circ}$ Visconde de Vila Nova de Souto del Rei, que o autor indica como sendo 1836, ou, ainda, considerar o $2^{\circ}$ Visconde D. António José de Almada e Melo como sendo o $1 .^{\circ}$. CANEDO, 1993: $565-566$.

92 http://www.arquivisticahistorica.fcsh.unl.pt/index.php/arquivo-almada-lencastre-basto.

93 ANTT - Instituto Superior das Bibliotecas e Arquivos, cx. 329, proc. 274 e Arquivo do 
recolher na BNP, nomeadamente correspondência ou outra documentação trocada entre as herdeiras do arquivo e a direção da BNP, que levaria ao processo de compra e autos de entrega do mesmo em 1974.

Para o estabelecimento do quadro orgânico do sistema de informação Almada Lencastre Bastos, que engloba os RAA dos produtores e acumuladores, propomos a criação de secções a partir dos nomes de família presentes nas subsecções, através de associações onomásticas dos apelidos. No caso de associação de apelidos semelhantes, a diferenciação far-se-á pelo acrescento de numeração romana, numa primeira abordagem, uma vez que as subsecções serão necessariamente diferentes, quanto mais não seja pelas suas datas de existência.

O quadro de classificação visa reconstituir as diversas gerações que compõem as famílias Almada e Melo e Pereira Forjaz, e que terá tantos sistemas ou subsistemas, dotados de organicidade e funcionalidade, quantos as famílias aliadas por sucessivas alianças matrimoniais ou relacionadas no âmbito de instituições onde determinados elementos da família desempenharam cargos. No caso em estudo, o sistema de informação Almada Lencastre Bastos e os subsistemas (as famílias e as instituições relacionadas, como acabámos de referir) irá ser organizado da seguinte forma94:

\section{Sistema Almada e Lencastre Bastos}

Secção 01. Pereira Forjaz Coutinho. Família, Condes da Feira. 1820-1827.95

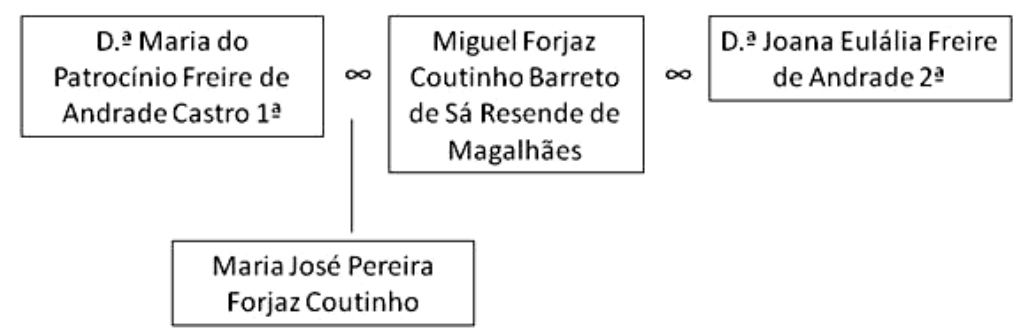

Figura 1 - Organograma da secção 01

\footnotetext{
Arquivo, n. ${ }^{\circ} 331$, cx. 146, proc. 91 - Aquisição do Arquivo Lencastre Bastos.

94 A título de exemplo apresenta-se esquematicamente o quadro orgânico-funcional e subsistemas de informação referentes à família Pereira Forjaz Coutinho, Condes da Feira. 1820-1827.

95 Secção correspondente a cada geração identificada pelos apelidos fortes da família num dado tempo.
} 
Subsecção 01. 01. D. Miguel Forjaz Coutinho Barreto de Sá Resende de Magalhães. 1769-1827 e D. ${ }^{a}$ Maria do Patrocínio Freire de Andrade Castro. 1767-1800.96

D. Miguel Forjaz Coutinho Barreto de Sá Resende de Magalhães (17691827) casou com D. ${ }^{a}$ Maria do Patrocínio Freire de Andrade Castro (17671800) em 1799, filha de Fernando Martins Freire de Andrade e Castro e de sua segunda mulher D. Joana Isabel de Lencastre Forjaz. Em 1800 tiveram uma filha que faleceu com apenas 6 meses de idade. Com este casamento estabeleceu-se a ligação com a família Freire de Andrade, da qual existem alguns documentos no arquivo.

\section{Ver Subsistema Freire de Andrade}

Subsecção 01. 02. D. Miguel Forjaz Coutinho Barreto de Sá Resende de Magalhães. 1769-1827 e D. ${ }^{a}$ Joana Eulália Freire de Andrade. 1763-1823.

D. Miguel Forjaz Coutinho Barreto de Sá Resende de Magalhães (17691827) casou com D. ${ }^{a}$ Joana Eulália Freire de Andrade (1763-1823) em 1803, filha de D. José António Freire de Andrade, 2. ${ }^{\circ}$ Conde de Bobadela, e de D. ${ }^{a}$ Antónia Xavier de Lencastre de Almeida e Bourbon. D. ${ }^{a}$ Joana era viúva de D. João de Faro e Sousa, Conde do Vimieiro. Com este casamento estabeleceu-se a ligação com a família Faro e Sousa, da qual existem documentos no arquivo.

Ver Subsistema Faro e Sousa. Família, Condes do Vimieiro

Subsecção 01. 03. D. Miguel Forjaz Coutinho Barreto de Sá Resende de Magalhães. 1769-1827.97

Dados biográficos e de carreira.

Ver Subsistema Secretaria de Estado dos Negócios Estrangeiros, Mar e Guerra

Ver Subsistema .... etc. ${ }^{a}$

96 As subsecções correspondentes ao casal, cada uma tendo aberta uma subsecção a fim de incluir documentação não relativa ao casal, mas à sua individualidade, antes e após matrimónio, debaixo da qual será descrita toda a documentação temática patrimonial e outra respeitante ao casal e trajetória pessoal.

97 A esta subsecção está, para já, associado o juiz do tombo dos Morgados de Freiriz e Penegate, João Jerónimo do Couto de Castro e Sousa (17---1831), como autor material de vária documentação existente no arquivo e que desempenhou o cargo desde 1812 a 1827, ano da morte do seu patrono. GAGO, 2015. 
Subsecção 01. 04. D. ${ }^{a}$ Maria do Patrocínio Freire de Andrade Castro. 1767-1800.

Dados biográficos.

Subsecção 01. 05. D. ${ }^{a}$ Joana Eulália Freire de Andrade. 1763-1823.

Dados biográficos.

Em cada secção (geração) onde há documentos de pessoas não identificadas ou relacionadas organicamente com o produtor, é criada uma subsecção, que surge no final com a indicação de não identificados, e que poderá a qualquer momento ser integrada quando surgirem novos dados.

Finalmente, por ordem alfabética das tipologias surgem em cada secção as séries e as subséries, os documentos compostos e simples e só depois, também alfabeticamente, os documentos da série funcional, distribuídos pelo respetivo contexto orgânico.

\section{Inconformidades detetadas no preenchimento de RAA na base ICA-AtoM}

Segundo as ODA, para uma identificação unívoca, um dos requisitos do preenchimento de um RAA, é colocarem-se as datas de nascimento, fundação e encerramento ou morte de uma determinada entidade. Neste caso dos arquivos de família, a data da fundação da família (geralmente coincidente com a do casamento entre a) e b)) ou, no caso de pessoas singulares, as datas de nascimento e morte. O que verificámos foi que no preenchimento da base ICA-AtoM, ao colocarmos as datas no título do RAA, as mesmas ficam associadas à hiperligação. Havendo uma alteração de data, apesar de se gravarem os novos dados, a hiperligação mantém a data antiga.

Exemplo:

D. António José de Almada Melo Velho e Lencastre, $4^{\circ}$ visconde

http://www.arquivisticahistorica.fcsh.unl.pt/index.php/lencastre-antonio-jose-de-almada-melo-velho-e-1805-1836

As datas registadas foram as datas que haviam sido recolhidas em bibliografia, nomeadamente as fornecidas por Fernando Canedo na obra já citada98. Por investigação posterior verificou-se que as mesmas estavam erradas, sendo as datas corretas: 1805-1863, comprovadas por registos

\footnotetext{
98 CANEDO, 1993, vol. I: 566.
} 
paroquiais. Para evitar esta duplicação de dados criada pelo programa, optámos por gravar provisoriamente o RAA apenas com o nome antes de colocar a data e assim qualquer alteração não entra em inconformidade com a hiperligação. A colocação da data é obrigatória pelas normas internacionais e fundamental perante casos de homonímia, em que a data funciona como termo de desambiguação.

Ainda no que se refere às datas, sendo um campo obrigatório, foram colocadas a seguir ao nome da pessoa singular ou família, precedidas de ponto final.

Ex: Lencastre, D. António José de Almada Melo Velho. 1805-1863, 4. ${ }^{\circ}$ visconde de Vila Nova de Souto del Rei.

Para datas desconhecidas, colocámos as datas de atividade, como datas exatas ou críticas, entre parêntesis retos, com o elemento "flor.", de "floruit" ou "c.", de "circa". A data provável pode figurar entre parênteses retos e interrogada ([?]), ou ainda com outras variantes previstas nas normas 99

No que diz respeito aos RAA de todos quantos tenham títulos nobiliárquicos, segundo as ODA e ISAAR, apontam para o título nobiliárquico presente logo na forma autorizada de nome ${ }^{100}$. Para seguir esta norma implicou a alteração de todos os RAA que se encontravam nesta situação.

Quanto ao pré-título, enquanto componente qualificativo do ponto de acesso normalizado do nome da pessoa singular é obrigatório quando aplicável, e corresponde a um título que precede o nome próprio, podendo corresponder a um tratamento de cortesia. Em Portugal existem, como pré-títulos, Dom, que precede os nomes dos reis, príncipes, infantes, alto clero e nobreza e a sua forma feminina, Dona. Deve ser registado antes do nome, na sua forma abreviada101. Desta forma os RAA devem ser preenchidos da seguinte forma:

Ex: Lencastre, D. António José de Almada Melo Velho. 1805-1863, 4. ${ }^{\circ}$ visconde de Vila Nova de Souto del Rei.

As ODA preveem que quando uma pessoa singular recebe um título nobiliárquico através do casamento, deve ser referida, no ponto de acesso normalizado, como cônjuge do titulado. Dessa forma todas as esposas dos viscondes devem ser registadas como viscondessas. Efetivamente, nos seus registos de óbito é frequente essa denominação, como por exemplo no registo de óbito de D. ${ }^{a}$ Maria Joana do Monte Forjaz da Câmara e Meneses

\footnotetext{
99 PORTUGAL, 2011: 232.

100 Id: 309.

101 Id: 322
} 
Coutinho de Sá Resende Magalhães, 3. ${ }^{a}$ viscondessa de Vila Nova de Souto del Rei.

Associado aos títulos nobiliárquicos estão ligados, como ficou dito, os tratamentos de "Dom" e "Dona". As ODA não referem até quando, temporalmente, se deve registar esta forma de tratamento. A situação não é de todo consensual, sobretudo pela legislação emanada à época acerca deste assunto, em que os decretos aboliam os títulos mas logo os restabeleciam de alguma forma102, mediante o pagamento de taxas. Esta situação manteve-se até 1995103, e sofreu algumas alterações em 2007104. Nesta linha de pensamento, optámos por colocar os RAA de todos aqueles que tiveram o seu nascimento anterior a 1910, com o pré-título de D. ou D. ${ }^{a}$, e os restantes, pós implantação da República, foram criados sem o pré-título105.

No caso de D. ${ }^{a}$ Maria José de Almada e Lencastre Sousa Teles, a última proprietária de parte do arquivo, como nasceu em 1900, pode-se-Ihe aplicar esta regra. No entanto, se houvesse nascido em 1911, poder-se-ia ter mantido o mesmo tratamento de $\mathrm{D}^{\text {a? }}$ ? O mesmo se refere ao título de Viscondessa de Vila Nova de Souto del Rei, para o qual foi autorizada ser a representante do título, por alvará do Conselho de Nobreza de 26 de junho de 1980 e representante do $10 .^{\circ}$ conde da Feira, por certificado do Conselho de Nobreza de 14 de junho de 1981? Que validade têm as deliberações deste conselho na atual legislação portuguesa? São questões jurídicas pertinentes que poderão ter implicações a nível de preenchimento de RAA, não só de famílias mas também de pessoas singulares, sobretudo em arquivos de família ainda em construção.

102 CORDEIRO, 2009: 19-57.

103 o Código do Registo Civil de 1995, referia no seu artigo 40. que o uso dos títulos nobiliárquicos portugueses só era permitido quando os interessados provassem que tinham direito à posse e uso de título existente antes de 5 de Outubro de 1910 e que as taxas devidas foram pagas. Admitia a lei a referência oficial a títulos adquiridos legitimamente após 1910, desde que tais títulos já existissem em 1910. A "posse e uso" atual de título anterior a 1910 só poderia ter sido adquirida na base das regras nobiliárquicas aplicáveis. Id.

104 Os n. OS 2, 3 e 4 foram suprimidos do artigo $400^{\circ}$ do Código do Registo Civil a partir das alterações introduzidas pelo Decreto-Lei . $^{\circ}$ 324/2007, de 29 de setembro, mas tal supressão não obsta a que se considere a validade ou invalidade do registo à luz da lei vigente anteriormente. Acordão do Supremo Tribunal de Justiça. Processo150/13.3YHLSB.L1.S1, de 2014-05-15. [Consult. 23 out. 2016]. Disponível em: <http://www.dgsi.pt/jstj.nsf/954f0ce6ad9dd8b980256b5f003fa814 19335c60e32d83d1e80257cdd005204fa?OpenDocument>.

105 Esta opção foi por nós tomada na impossibilidade de consulta do FNAA, que se encontra indisponível desde setembro de 2016. A consulta de outros RAA em diversos fundos arquivísticos não foi consensual. 
No final deste artigo ${ }^{106}$ apresenta-se um modelo de RAA criado para famílias e pessoas singulares, que pode ser utilizado como um guia de preenchimento de RAA em arquivos de família. O modelo foi realizado de acordo com a norma internacional ISAAR(CFP) e com as orientações estabelecidas pelas ODA, Parte II relativa à descrição de autoridades arquivísticas ${ }^{107}$. Os elementos considerados obrigatórios foram sempre preenchidos, bem como alguns elementos opcionais, quando se justificava. As exceções estão devidamente justificadas na tabela.

\section{Arquivistas e historiadores: a possível complementaridade}

Em 2004 Lucília Runa108 considerou, num encontro que reuniu na Torre do Tombo arquivistas e historiadores, fundamental que se reúnam e organizem equipas interdisciplinares, onde arquivistas e historiadores ou outros investigadores especialistas em diferentes épocas e domínios de conhecimento, contribuam para a descrição e posterior disponibilização de fundos documentais. O mesmo foi também defendido por Kathleen Marquis, em texto de 2007109, na linha do que Francis X. Blouin e William G. Rosenberg110 têm afirmado, ao chamar a atenção para o papel de mediação e cooperação entre arquivistas e historiadores.

É do conhecimento público que os arquivos, como outras demais entidades detentoras de arquivo, não detêm os recursos humanos necessários para poder criar e disponibilizar rapidamente RAA e toda a descrição pormenorizada dos arquivos que detêm à sua guarda, não só pelas incorporações contínuas de documentos, como por todos os trabalhos de avaliação documental, de serviços ao utilizador, etc. ${ }^{a}$ Assim, a exemplo do que acima foi enunciado, consideramos também que esse trabalho poderia ser complementado com recurso a equipas multidisciplinares, onde os diversos especialistas poderiam contribuir para um melhor conhecimento do produtor mas também do contexto de produção documental.

Como já foi referido, a descrição arquivística tal como hoje a consideramos é uma matéria relativamente recente, com um suporte teórico ainda

\footnotetext{
106 Ver Anexos, no fim do artigo.

107 PORTUGAL, 2011.

108 RUNA, 2004: 150

109 MARQUIS, 2007: 37-38.

110 BLOUIN, 2007; 2011.
} 
em construção, como se denota pelas várias versões das ODA. Os esforços desenvolvidos na normalização da descrição de documentos de arquivo e na disseminação e disponibilização dos arquivos em rede permitem o acesso à informação de forma eficaz e têm dado resposta às principais necessidades do utilizador. No entanto não são ainda suficientes para dar resposta a todas as suas exigências, nomeadamente no que respeita à identificação, estudo e acompanhamento da evolução das entidades produtoras de arquivos, às suas alterações de nome, e/ou às suas relações de sucessão e de complementaridade funcional, entre outras, que se repercutem na correta identificação e história da entidade. É assim fundamental, do nosso ponto de vista, que se promova o diálogo construtivo e cooperante entre os vários campos de saber, arquivístico e histórico, para um melhor conhecimento do património cultural português.

\section{Conclusão}

Até à publicação das normas de descrição arquivística de registos de autoridade, a definição de modelos que se ajustassem e adaptassem às várias tradições e práticas arquivísticas era um problema recorrente. Os profissionais portugueses não tinham o hábito de produzir textos, sistematizar e uniformizar procedimentos, nem fazer o elenco dos problemas e formular formas de os resolver. Cada serviço de arquivo tinha as suas próprias práticas e, mesmo dentro de cada um, a uniformidade não era uma constante no que respeitava, por exemplo, à elaboração de instrumentos de descrição, quer no que respeitava ao conteúdo como à estrutura.

A preocupação com a elaboração de normas internacionais para a descrição arquivística resulta de um quadro global de desenvolvimento da sociedade e do seu acesso ao conhecimento. Desta forma, o desenvolvimento de normas internacionais enquadra-se no contexto da assunção da arquivística como uma disciplina da ciência da informação, autónoma e ao impacto das tecnologias de informação no tratamento e recuperação dessa mesma informação.

Com a criação da ISAAR(CPF) e das suas aplicações, como as ODA no caso português, ou as NEDA no caso espanhol, a descrição de autoridades arquivísticas caminha no sentido da sua unificação sob uma mesma forma descritiva, uniformizadora e unívoca. As famílias e as pessoas singulares, a elas pertencentes, são assim descritas e relacionadas, criando pontos de acesso entre elas, o que permite ao investigador cruzar informação. A sua 
incorporação num ficheiro nacional de autoridades arquivísticas poderá permitir a recuperação de informação, de uma forma sistémica, em qualquer entidade detentora (arquivo, biblioteca, museu) que tenha algum tipo de informação sobre um determinado personagem ou família.

Assim, a partilha de informações - e acima de tudo sobre os produtores de arquivos - é fundamental para a nova forma de descrever arquivos, uma partilha que é estimulada pela expansão da informática e, principalmente, pela rede, que levou ao reposicionamento dos objetivos e, acima de tudo, à alteração dos instrumentos de descrição arquivística. O aparecimento da internet contribuiu para, no que respeita às entidades detentoras de arquivos, quebrar a qualidade autorreferencial tão comuns nos arquivistas e nas entidades onde trabalham, sublinhando vigorosamente a necessidade de encontrar ferramentas que tornam possível a criação de descrições arquivísticas a nível local, nacional e internacional.

O controlo dos registos de autoridade constitui uma ferramenta dinâmica de suporte das descrições arquivísticas e do seu acesso, pois permite expressar as complexas relações entre os arquivos e os seus protagonistas. Constituem importantes auxiliares do trabalho, garantes de uma maior coerência e consistência da descrição, da sua normalização, controlando a subjetividade inerente a qualquer representação humana da realidade. Daí a importância de constituição de autoridades, unívocas, reguladas como o Ficheiro Nacional de Autoridades Arquivísticas, com o objetivo de facilitar o acesso por parte dos utilizadores, permitindo que os mesmos possam aceder de um único ponto a vários recursos, simultaneamente, sem terem de consultar diversos instrumentos de descrição documental de fundos para verificar a existência ou ausência de documentos produzidos por uma mesma pessoa.

Na mesma linha de pensamento está a criação de registos de autoridade na plataforma ICA-AtoM, ao constituir uma mais valia para as teses que estão a ser desenvolvidas no âmbito da frequência de cursos de Doutoramento em Arquivística Histórica e descrição de arquivos de família, pois permitem não só criar uma base de dados de trabalho como, e sobretudo, identificar univocamente os seus elementos e respetivas famílias e estabelecer relações entre elas. A apresentação de resultados deste trabalho é ainda um processo em construção, com várias condicionantes no que se refere ao preenchimento dos campos de descrição, como verificámos, mas que esperamos possa constituir uma ferramenta de trabalho para todos os investigadores de História das Épocas Medieval e Moderna portuguesas.

O estudo das famílias e dos seus elementos e a criação de RAA é de inegável importância para o conhecimento e compreensão dos arquivos, e 
do âmbito em que estes foram produzidos, revelando-se como uma mais valia para a comunidade, científica e não só, pelo contributo dos seus conteúdos para o FNAA, e, em última análise, para a afirmação e valorização da Arquivística, enquanto área científica responsável por práticas de tratamento e difusão da história e memória, pela produção e disponibilização de instrumentos que possibilitem a identificação dos arquivos e o acesso à informação, por parte do cidadão.

\section{Fontes e Bibliografia}

\section{Fontes Manuscritas}

Arquivo Nacional da Torre do Tombo (ANTT) - Instituto Superior das Bibliotecas e Arquivos, cx. 329, proc. 274.

Arquivo Nacional da Torre do Tombo (ANTT) - Arquivo do Arquivo, n. ${ }^{\circ} 331$, cx. 146, proc. 91 - Aquisição do Arquivo Lencastre Bastos.

\section{Bibliografia}

ALVES, Ivone et alii (1993) - Dicionário de terminologia arquivística. $1^{\text {a }}$ ed. Lisboa: Instituto da Biblioteca Nacional e do Livro.

ARAÑA CRUZ, Jonathan e HERRERA TEJADA, Clara (2001) - ICA-AtoM, una buena herramienta para la difusión de los archivos en la web. Disponível em <https://www. ateneodemadrid.com/index.php/esl/Media/Files/ICA-AtoM-una-buena-herramientapara-la-difusion-de-los-archivos-en-la-web> (acedido em 23/10/2016).

BLOUIN, Francis X. Jr. e ROSENBERG, William G. (2007) - Archives, Documentation and Institutions of Social Memory. Essays from the Sawyer Seminar. EUA; Michigan University Press.

BLOUIN, Francis X. Jr. e ROSENBERG, William G. (2011) - Processing the Past. Contesting Authority in History and the Archives. Oxford: Oxford University Press.

BONAL ZAZO, J. L. (2000) - La normalización: base del análisis documental en los archivos. Scire. 6, 1 (en.-jun. 2000), p. 55-75.

BONAL ZAZO, J. L. (2001) - La descripción archivistica normalizada, origen, fundamentos, princípios y técnicas. Gijon: Ed. Trea.

BUSHEY, Jessica (2012) - International Council on Archives (ICA) "Access to Memory" (AtoM): open-source software for archival description. Disponível em <https://www. ica-atom.org/download/ICA-AtoM_JBushey.pdf> (acedido em 23/10/2016).

CANEDO, Fernando de Castro da Silva (1993) - A descendência portuguesa de el-rei D. João II. vol. I-III. Lisboa: Ed. Gama.

CONSELHO INTERNACIONAL DE ARQUIVOS (2004) - ISAAR(CPF): norma internacional de registos de autoridade arquivística para pessoas colectivas, pessoas singulares e famílias. $2^{\text {a }}$ ed. Lisboa: Instituto dos Arquivos Nacionais/Torre do Tombo.

CONSELHO INTERNACIONAL DE ARQUIVOS (2002) - ISAD(G): norma geral internacional de descrição arquivística. $2^{\text {a }}$ ed. Lisboa: Instituto dos Arquivos Nacionais/Torre do Tombo. 
COOK, Terry (1993) - The concept of the archival fonds in the post-custodial era: theory, problems and solutions. Archivaria. 35, p. 24-37. Disponível em <http://journals.sfu. ca/archivar/index.php/archivaria/article/view/1 1882/12835> (acedido em 23/10/2016).

CORDEIRO, António Menezes (2009) - Títulos nobiliárquicos e registo civil - A insconstitucionalidade da reforma de 2007. Revista da Ordem dos Advogados. 69, p. 19-57. Disponível em <http://www.oa.pt/Conteudos/Artigos/detalhe_artigo. aspx?idsc=84042\&ida=84317 > (acedido em 23/10/2016).

COX, Richard (1994) - Standardizing archival practices: a tool for the information age. Archivum. 39, p. 165-179.

COUTURE, Carol (2001) - L'archivistique à l'aube du troisième millénaire. Cadernos BAD. 1, p. 1-14.

DURANCE, Cynthia J. (1993) - Authority control: beyond a bowl of alphabet soup. Archivaria. 35, p. 38-46. Disponível em <http://journals.sfu.ca/archivar/index.php/ archivaria/article/view/11883/12836> (acedido em 23/10/2016).

ENCONTRO NACIONAL DE ARQUIVOS MUNICIPAIS, 8, Vila Real, 2007 - Conclusões. Disponível em < http://www.apbad.pt/Downloads/GT_Downloads/ Conclusoes_8EncontroArqMun.pdf> (acedido em 8/3/2017).

ESPANHA. Ministerio de Educación, Cultura y Deporte. Comisión de Normas Españolas de Descripción Archivística (2012) - Modelo Conceptual de Descripción Archivística y Requisitos de Datos Básicos de las Descripciones de Documentos de Archivo, Agentes y Funciones. Parte 1: Tipos de Entidad. Parte 2: Relaciones. Documento de la CNEDA (18-06-2012). Disponível em <http://www.mecd.gob.es/dms/mecd/cultura-mecd/areas-cultura/archivos/mc/cneda/documentacion/NEDA_MCDA_P1_ P2_20120618-pdf/NEDA_MCDA_P1_P2_20120618.pdf> (acedido em 23/10/2016).

FUENTE, Francisco de la (2011) - D. Miguel Pereira Forjaz, O organizador da luta contra Napoleão. Lisboa: Tribuna da História.

GAGNON-ARGUIN, Louise (1992) - Une introduction au contrôle d'autorité pour le traitement des noms propres en archivistique. Ottawa: Bureau canadien des archivistes.

GAGNON-ARGUIN, Louise (2012) - Les normes de description des documents d'archives: vers l'accès à l'information patrimoniale. Documentation et bibliothèques. 58, 3, p 109-117.

GAGO, Alice Borges (2015) - Serving the Counts of Feira in the 19th's: João Jerónimo do Couto de Castro e Sousa, archivist and judge. In ROSA, Maria de Lurdes, HEAD, Randolph C. (eds.) - Rethinking the archive in pre-Modern Europe: family archives and their inventories from the 15th to the 19th century. Lisboa: IEM, p. 83-88.

GRUPO DE TRABALHO ATOM DA REDE DE ARQUIVOS DO ALGARVE (coord.) (2016) AtoM work in progress. Livro de Actas. Algarve: Rede de Arquivos do Algarve. Disponível em <https://rededearquivosdoalgarve.files.wordpress.com/2016/11/livro-de-actas.pdf> (acedido em 20/11/2016).

GUEDES, Gracinda Maria Ferreira (2015) - A descrição normalizada de arquivos como condição sine qua non para a eficaz recuperação e comunicação da informação na Web. Boletim do Arquivo da Universidade de Coimbra. XXVIII, p. 191-210.

HEDLUND, Dhion C. e FLORES, Daniel (2014) - Análise e aplicação do software livre ICA-ATOM como ferramenta para descrição e acesso às informações do patrimônio documental e histórico do município de Santa Maria - RS. Informação Arquivística. Rio de Janeiro. 3, 1, p. 24-41. 
HEREDIA HERRERA, Antonia (2010) - La CNEDA: un nuevo modelo conceptual de descripción archivística. Arch-e: revista andaluza de archivos. 3. Disponível em <http:// www.juntadeandalucia.es/culturaydeporte/archivos_html/sites/default/contenidos/ general/revista/numeros/Numero_3/Galeria/03_03_11_Antonia_Heredia.pdf> (acedido em 23/10/2016).

INTERNATIONAL COUNCIL ON ARCHIVES (2007) - ISDF: International Standard for Describing Functions. 1. ${ }^{a}$ ed. Paris: ICAVCBPPS.

INTERNATIONAL COUNCIL ON ARCHIVES (2008) - ISDIAH: International Standard for Describing Institutions with Archival Holdings. 1. ${ }^{a}$ ed. Paris: ICA/CBPS.

INTERNATIONAL COUNCIL ON ARCHIVES. Committee on Best Practices and Standards. Sub-committee on archival description - Progress report for revising and harmonising ICA descriptive standards. Disponível em <http://www.ica.org/sites/default/files/ Report_for_revising_harmonising_description_standards.pdf> (acedido em 23/10/2016).

INTERNATIONAL COUNCIL ON ARCHIVES. Committee on Best Practices and Standards. Sub-committee on archival description - Relationships in archival descriptive systems. Disponível em <http://www.ica.org/sites/default/files/Relationships_archival_descriptive_standards.pdf> (acedido em 23/10/2016).

INTERNATIONAL COUNCIL ON ARCHIVES. Experts Group on Archival Description Records in contexts: a conceptual model for archival description. Consultation Draft v 0.1. Disponível em <http://www.ica.org/en/egad-ric-conceptual-model> (acedido em 8/3/2017).

ISO 639-2. (1998) - Codes for the representation of names of languages, Alpha - 3 code. Geneve: ISO.

ISO 8601. (2004) - Data elements and interchange formats - Information interchange: representation of dates and times. Geneva: ISO.

ISO 15924. (2004) - Codes for the representation of names of scripts. Geneve: ISO.

Instituto Português da Qualidade (1994) - NP 405-1: 1994 - Norma portuguesa para informação e documentação: Referências bibliográficas: documentos impressos. Lisboa: IPQ.

Instituto Português da Qualidade (1998) - NP 405-2: 1998 - Norma portuguesa para informação e documentação: Referências bibliográficas: material não livro. Lisboa: IPQ.

Instituto Português da Qualidade (2000) - NP 405-3: 2000 - Norma portuguesa para informação e documentação: Referências bibliográficas: documentos não publicados. Lisboa: IPQ.

Instituto Português da Qualidade (2002) - NP 405-4: 2002 - Norma portuguesa para informação e documentação: Referências bibliográficas: documentos electrónicos. Lisboa: IPQ.

Instituto Português da Qualidade (2005) - NP 4041: 2005 - Norma portuguesa para informação e documentação: Terminologia arquivística: conceitos básicos. Lisboa: IPQ.

Instituto Português da Qualidade (1996) - NP EN 28601: 1996 - Norma portuguesa para dados e formatos de troca: Troca de informação: representação de datas e horas. Lisboa: IPQ. 
LAFUENTE URIÉN, Aranzazu (2014) - Archival authority control: an introduction to Encoded Archival Context for Corporate Bodies, Persons and Families (EAC-CPF). Disponível em <http://www.apex-project.eu/index.php/en/articles/184-archival-authority-control-an-introduction-to-encoded-archival-context-corporate-bodies-persons-and-families> (acedido em 23/10/2016).

LEME, Margarida (2012) - O Arquivo Costa no Arquivo Óbidos-Palma-Sabugal. In ROSA, Maria de Lurdes (org.) - Arquivos de Família, séculos XIII-XX:Que presente, que futuro? Lisboa: Instituto de Estudos Medievais, Centro de História de Além-Mar e Caminhos Romanos, p. 479-490.

LEROUX, Sébastien et alii (2012) - Ficheiro Nacional de Autoridades Arquivísticas. interoperabilidade e operação colaborativa. In CONGRESSO NACIONAL DE BIBLIOTECÁRIOS, DOCUMENTALISTAS E ARQUIVISTAS, 11, Lisboa, 2012 - Integração, Acesso e Valor Social: Atas. Disponível em <http://www.bad.pt/publicacoes/index.php/congressosbad/article/view/338> (acedido em 23/10/2016).

MARQUES, Patrícia Cardoso (2013) - O Arquivo Castro/Nova Goa: construção de catálogo. A aplicação do modelo sistémico. Lisboa, [s. n.] (Dissertação de Mestrado em Ciências da Informação e da Documentação - Arquivística apresentada à Universidade Nova de Lisboa).

MARQUIS, Kathleen, (2007) - Not Dragon at the Gate but Research Partner: The Reference Archivists as Mediator. In BLOUIN, Francis X. Jr.; ROSENBERG, William G. (eds.) - Archives, Documentation and Institutions of Social Memory. Essays from the Sawyer Seminar. EUA: Michigan University Press, p. 36-42.

MORAIS, Cláudia Santos Pires de (2013) - Estudo Orgânico-Funcional e Tratamento Arquivístico dos Concursos para Obtenção do Diploma de Arquiteto realizados na Escola de Belas Artes do Porto: utilização do software ICA-AToM. Porto, [s. n.] (Tese de Mestrado em Ciência da Informação apresentada à Universidade do Porto).

NÓVOA, Rita Luís Sampaio da (2016) - O Arquivo Gama Lobo Salema e a produção, gestão e usos dos arquivos de família nobre nos séculos XV-XVI. Lisboa, [s. n.] (Dissertação de Doutoramento em História - especialização em Arquivística Histórica apresentada à Universidade Nova de Lisboa).

PEIXOTO, Pedro Abreu (1994) - Aspectos essenciais para o desenvolvimento de uma política de arquivos. Os arquivos de família. Cadernos BAD. 1, p. 43-48.

PEIXOTO, Pedro de Abreu (1999) - A aplicação das ISAD (G) aos arquivos de família. Páginas a\&b. 4, p. 55-70.

PINTO, Pedro (2012) - O Arquivo da Família Almada Lencastre Basto (Casa de Souto de El-Rei e Casa da Feira) na Biblioteca Nacional: propostas de exploração no âmbito da elaboração de um catálogo. In ROSA, Maria de Lurdes (org.) - Arquivos de Família, séculos XIII-XX: Que presente, que futuro? Lisboa: Instituto de Estudos Medievais, Centro de História de Além-Mar e Caminhos Romanos, p. 307-341.

PORTUGAL. Direção-Geral de Arquivos (2008a) - Modelo para um Ficheiro Nacional de Autoridades Arquivísticas (FNAA). Lisboa: DGARQ. Disponível em <http://arquivos.pt/ wp-content/uploads/sites/11/2009/10/fnaa.pdf> (acedido em 23/10/2016).

PORTUGAL. Direção-Geral de Arquivos (2008b) - Rede Portuguesa de Arquivos (RPA): fundamentos para o seu desenvolvimento e gestão. Módulo 1: Modelo Conceptual. Lisboa: DGARQ. Disponível em <http://arquivos.pt/wp-content/uploads/ sites/11/2009/10/rpa_mc.pdf> (acedido em 23/10/2016). 
PORTUGAL. Direção-Geral de Arquivos (2008c) - Rede Portuguesa de Arquivos (RPA): fundamentos para o seu desenvolvimento e gestão. Módulo 2: Modelo Lógico. Lisboa: DGARQ. Disponível em <http://arquivos.pt/wp-content/uploads/ sites/11/2009/10/rpa_ml.pdf> (acedido em 23/10/2016).

PORTUGAL. Direção-Geral de Arquivos. Grupo de Trabalho de Normalização da Descrição em Arquivo (2011) - Orientações para a descrição arquivística. 3. ${ }^{a}$ v. Lisboa: DGARQ. Disponível em <http://act.fct.pt/wp-content/uploads/2014/05/ODA-3\%C2\%AAvers\%C3\%A3o.pdf> (acedido em 23/10/2016).

PORTUGAL. Supremo Tribunal de Justiça (2014) - Acordão do Supremo Tribunal de Justiça. Processo150/13.3YHLSB.L1.S1, de 2014-05-15. Disponível em <http://www. dgsi.pt/jstj.nsf/954f0ce6ad9dd8b980256b5f003fa814/9335c60e32d83d1e80257cd d005204fa? OpenDocument> (acedido em 23/10/2016).

RIBEIRO, Fernanda (1996) - Indexação e controlo de autoridade em arquivos. Porto: Câmara Municipal-Arquivo Histórico.

RODRIGUES, Ana Margarida de Almeida Casimiro (2013) - Estudo orgânico-funcional das entidades tutelares da Agricultura (1918-2013): Uma contribuição para o Ficheiro Nacional de Autoridades Arquivísticas (FNAA). Lisboa: [s. n.] (Dissertação de Mestrado em Ciências da Informação e da Documentação - Arquivística apresentada à $\mathrm{FCSH}-\mathrm{UNL}$ ).

ROE, Kathleen (1993) - Enhanced Authority Control: Is It Time? Archivaria. 35, p. 119129. Disponível em <http://journals.sfu.ca/archivar/index.php/archivaria/article/ view/11891/12844> (acedido em 23/10/2016).

ROSA, Maria de Lurdes (2009) - Problemáticas históricas e arquivísticas actuais para o estudo dos arquivos de família portugueses (Épocas medieval e moderna). Revista de História da Sociedade e da Cultura. 9, p. 9-42.

RUNA, Lucília (2004) - Arquivos de personalidades políticas no IAN/TT. In Olhares cruzados entre Arquivistas e Historiadores: mesas-redondas na Torre do Tombo. Lisboa: Instituto dos Arquivos Nacionais/Torre do Tombo, p. 147-150.

RUNA, Lucília (2007) - Orientações para a descrição arquivística: normalizar para partilhar e recuperar. In Actas do Congresso Nacional de Bibliotecários, Arquivistas e Documentalistas. 9, p. 1-10. Lisboa: BAD. Disponível em <http://bad.pt/publicacoes/ index.php/congressosbad/article/view/588/430> (acedido em 23/10/2016).

RUNA, Lucília (2011) - A Descrição Arquivística. In CRUZ MUNDET, José Ramón (dir.) Administración de documentos y archivos. Textos fundamentales. Madrid: CAA, p. 161-214.

RUNA, Lucília e SOUSA, Joana Braga (2003) - Normalizar a descrição em arquivo: questionar, reflectir e aplicar. Cadernos BAD. 2, p. 80-108. Disponível em <http://www. apbad.pt/CadernosBAD/Caderno22003/Runa.pdf> (acedido em 23/10/2016).

SANTOS, Andrea Gonçalves dos e FLORES, Daniel (2012) - A utilização de software livre na preservação documental: experiência com o ICA-AtoM. In CONGRESSO INTERNACIONAL INTERDISCIPLINAR EM SOCIAIS E HUMANIDADES, 1, Niterói, 2012. Disponível em <http://www.aninter.com.br/ANAIS\%20l\%20CONITER/GT11\%20 Informa\%E7\%E30, \% 20 educa \%E7\%E30\%20e\%20tecnologias/A\% 20 UTILIZA \% C $7 \%$ C $30 \% 2$ ODE \% 20 SOFTWARE \% 2 OLIVRE \% 20 NA \% 20 PRESERVA\%C7\%C30\%20DOCUMENTAL\%20EXPERI\%CANCIA\%20COM\%20 O\%20ICA-AtoM\%20-\%20Trabalho\%20Completo.pdf> (acedido em 23/10/2016). 
SILVA, Armando Malheiro da et alii (2002) - Arquivística: teoria e prática de uma Ciência da Informação. Porto: Afrontamento.

SILVA, Armando Malheiro da (1997) - Arquivos de Família e Pessoais. Bases teórico-metodológicas para uma abordagem cientifica. In Arquivos de Família e Pessoais: Seminário. Vila Real: APBAD, p. 51-106.

SILVA, Armando Malheiro da (2004) - Arquivos familiares e pessoais. Bases científicas para aplicação do modelo sistémico e interactivo. Revista da Faculdade de Letras. Ciências e técnicas de Património. I s., vol. III. Porto: Universidade do Porto, p. 55-84.

SILVA, Armando Malheiro da, org. (2005) - A casa de Mateus e a memória. O acesso sistémico a séculos de documentos na era da informação. In Casa de Mateus. Catálogo do Arquivo. Vila Real: Fundação da Casa de Mateus, p. 13-31.

SILVÉRIO, Carla Alexandra Serapicos de Brito (2008) - Contributo para a construção do Ficheiro Nacional de Autoridades Arquivísticas. Lisboa: [s. n.] (Relatório de Estágio de Mestrado em Ciências da Informação e da Documentação - Arquivística apresentado à Universidade Nova de Lisboa).

SIMÕES, Sérgio Manuel Duarte Simões (2010) - Metodologia de avaliação de aplicações para descrição de arquivo definitivo. Lisboa: [s. n.] (Tese de Mestrado em Ciências da Documentação e Informação - Biblioteconomia e Documentação apresentada à Universidade de Lisboa).

SOUSA, Maria João da Câmara Andrade e (2012) - O Arquivo da Casa de Belmonte: o que o tempo (ainda) não apagou. In ROSA, Maria de Lurdes (org.) - Arquivos de Família, séculos XIII-XX: Que presente, que futuro? Lisboa: Instituto de Estudos Medievais, Centro de História de Além-Mar e Caminhos Romanos, p. 491-506.

THIBODEAU, Sharon (1995) - Archival context as archival authority record: the ISAAR(CPF). Archivaria. 40, p. 75-85. Disponível em <http://journals.sfu.ca/archivar/ index.php/archivaria/article/view/12097/13084> (acedido em 23/10/2016).

TRINDADE, Cátia João Matias (2012) - A importância da criação de registos de autoridade arquivistica para entidades produtoras de arquivos. $O$ caso das entidades colectivas públicas, criadas na segunda metade do século XX, produtoras de arquivos de política científica em Portugal. Lisboa: [s. n.]. (Tese de Mestrado em Ciências da Informação e da Documentação - Área de Especialização em Arquivística apresentada à Universidade Nova de Lisboa).

VAN GARDEREN, Peter (2009) - The ICA-AtoM project and tecnology. In ASSOCIATION OF BRAZILIAN ARCHIVISTS - Third Meeting on Archival Information Databases, Rio de Janeiro, 2009 Disponível em <https://www.ica-atom.org/download/VanGarderen_ ThelCA-AtoMProjectAndTechnology_AAB_RioDeJaniero_16-17March2009.pdf> (acedido em 23/10/2016).

VENTURA, Maria Isabel de Almeida (2011) - O Arquivo Paço de Calheiros: uma abordagem sistémica. Porto: [s. n.] (Dissertação de mestrado em Ciência da Informação apresentada à Universidade do Porto).

VITALI, Stefano (2004) - Authority Control of Creators and the Second Edition of ISAAR(CPF), International Standard Archival Authority Record for Corporate Bodies, Persons, and Families. Cataloging \& Classification Quarterly. 38, p. 185-199. 


\section{Sítios Web}

ARCHIVES PORTAL EUROPE - [Em linha]. Disponível em <http://www.archivesportaleurope.net/home> (acedido em 23/10/2016).

ARCHIVISTES - [Em linha]. Disponível em <http://www.archivistes.org/Notices-d-autoriteproducteurs-1781\#la-demarche-redactionnelle-des> (acedido em 23/10/2016).

INTERNATIONAL COUNCIL ON ARCHIVES - [Em linha]. Disponível em <http://www.ica. org > (acedido em 31/05/2015).

PORTUGAL. Câmara Municipal de Albufeira - Arquivo Municipal. [Em linha]. Disponível em <http://arquivo.cm-albufeira.pt/> (acedido em 23/10/2016).

PORTUGAL. Confederação Geral dos Trabalhadores Portugueses - Intersindical Nacional - Centro de Arquivo e Documentação. [Em linha]. Disponível em <http://cad.cgtp. pt/> (acedido em 23/10/2016).

PORTUGAL. Direcção-Geral do Livro, dos Arquivos e das Bibliotecas - Sítio Web. Disponível em <http://dglab.gov.pt/> (acedido em 23/10/2016).

PORTUGAL. Direcção-Geral do Livro, dos Arquivos e das Bibliotecas - Digitarq [Em linha]. Disponível em <http://digitarq.dgarq.gov.pt/> (acedido em 23/10/2016).

PORTUGAL. Direcção-Geral do Livro, dos Arquivos e das Bibliotecas - Ficheiro Nacional de Autoridades Arquivisticas [Em linha]. Disponível em <http://autoridades.arquivos. pt> (acedido em 31/05/2015).

PORTUGAL. Direcção-Geral do Livro, dos Arquivos e das Bibliotecas - Portal Português de Arquivos [Em linha]. Disponível em <http://portal.arquivos.pt> (acedido em 23/10/2016).

PORTUGAL. Direcção-Geral do Livro, dos Arquivos e das Bibliotecas - Rede Portuguesa de Arquivos [Em linha]. Disponível em <http://arquivos.pt> (acedido em 23/10/2016).

PORTUGAL. Direcção-Geral do Património Cultural - Matriznet. [Em linha]. Disponível em <http://www.matriznet.dgpc.pt/matriznet/home.aspx> (acedido em 11/3/2017).

PORTUGAL. Partido Social Democrata - Arquivo da Social Democracia. [Em linha]. Disponível em <http://fotos.psd.pt/atom/index.php/psd-partido-social-democrata-2> (acedido em 23/10/2016).

PROJECTO INVENT.ARQ. - [Em linha]. Disponível em <http://www.inventarq.fcsh.unl.pt index.php/?sf_culture=pt> (acedido em 23/10/2016). 


\section{ANEXOS}

\section{Modelo de Preenchimento de um RAA pessoa singular e familiar}

\begin{tabular}{|l|l|l|}
\hline \multicolumn{2}{|c|}{ 1. Zona da Identificação } \\
\hline 1. 1 Tipo de entidade & $\begin{array}{l}\text { Preenchimento } \\
\text { O111 }\end{array}$ & $\begin{array}{l}\text { O objetivo deste elemento de informação é a } \\
\text { identificação unívoca do tipo de entidade descrita da } \\
\text { pessoa coletiva, pessoa singular ou família, produtoras } \\
\text { de fundos documentais 112. } \\
\text { Considerou-se para a elaboração deste trabalho as } \\
\text { categorias "pessoa singular" e "família". }\end{array}$ \\
\hline $\begin{array}{l}\text { 1.2 Formas autorizadas } \\
\text { do nome }\end{array}$ & $\begin{array}{l}\text { Preenchimento } \\
\text { O }\end{array}$ & $\begin{array}{l}\text { O objetivo deste elemento é a criação de um ponto de } \\
\text { acesso autorizado que identifique de forma unívoca a } \\
\text { pessoa coletiva, a pessoa singular ou a família. } \\
\text { Para cada pessoa singular aqui descrita foi utilizada } \\
\text { uma forma autorizada do nome, de acordo com } \\
\text { as orientações relativas à Escolha e construção de } \\
\text { pontos de acesso normalizados, III Parte das ODA113. } \\
\text { Utilizar datas, lugares, jurisdições, ocupações, epítetos } \\
\text { e outros qualificativos apropriados para distinguir a } \\
\text { forma autorizada do nome das de outras entidades } \\
\text { com nomes semelhantes. O qualificativo "data" é } \\
\text { uma componente obrigatória do ponto de acesso } \\
\text { normalizado do nome da pessoa singular, pois } \\
\text { revela-se fundamental para criar a identificação } \\
\text { unívoca de pessoas com o mesmo nome, mas } \\
\text { com datas de existência diferentes. As datas } \\
\text { apresentadas correspondem às datas extremas dos } \\
\text { anos de existência de cada uma das pessoas e foram } \\
\text { determinadas através da consulta de bibliografia. } \\
\text { nome }\end{array}$ \\
\hline $\begin{array}{l}\text { As componentes foram registadas pela ordem acima } \\
\text { estabelecida, sendo separadas por um ponto (.). }\end{array}$ \\
\hline $\begin{array}{l}\text { OP objetivo deste elemento de informação é registar as } \\
\text { diferentes formas autorizadas do nome das entidades } \\
\text { descritas noutras línguas ou escritas. } \\
\text { Tendo em conta que as pessoas aqui descritas } \\
\text { não possuíam nomes oficiais em outras línguas, o } \\
\text { preenchimento deste elemento não foi efetuado. }\end{array}$ \\
\hline
\end{tabular}

111 A legenda do quadro é a seguinte: O - Obrigatório; OA - Obrigatório se aplicável e OP Opcional.

112 Para a definição de "pessoa singular" e de "produtor" veja-se: PORTUGAL, 2011: 216-217.

113 Ib.: 306 e ss. 


\begin{tabular}{|c|c|c|}
\hline $\begin{array}{l}\text { 1. } 4 \text { Formas } \\
\text { normalizadas do } \\
\text { nome de acordo com } \\
\text { outras regras }\end{array}$ & $\begin{array}{l}\text { Preenchimento } \\
\text { OP }\end{array}$ & $\begin{array}{l}\text { Registar as formas normalizadas do nome da pessoa } \\
\text { coletiva, da pessoa singular ou da família, construídas } \\
\text { segundo outras normas que não as das ODA. } \\
\text { As formas normalizadas do nome de acordo com } \\
\text { outras regras permitem facilitar a partilha de } \\
\text { registos de autoridade entre diferentes comunidades } \\
\text { profissionais, nomeadamente com as bibliotecas, os } \\
\text { museus, etc. }\end{array}$ \\
\hline $\begin{array}{l}\text { 1. } 5 \text { Outras formas do } \\
\text { nome }\end{array}$ & $\begin{array}{l}\text { Preenchimento } \\
\text { OP }\end{array}$ & $\begin{array}{l}\text { O objetivo deste elemento de informação é registar } \\
\text { qualquer outro nome ou nomes da pessoa singular } \\
\text { ou família, não registados nos outros elementos de } \\
\text { informação da Zona da Identificação. Neste campo } \\
\text { registam-se outros nomes pelos quais a entidade possa } \\
\text { ser conhecida, tais como: } \\
\text { a) Outros nomes das pessoas singulares ou das } \\
\text { famílias, por exemplo mudanças de nome através do } \\
\text { tempo, incluindo pseudónimos, nomes de solteiro, } \\
\text { etc., e respetivas datas; } \\
\text { b) Nomes, e títulos que antecedem ou seguem os } \\
\text { nomes pessoas singulares e das famílias, ou seja, } \\
\text { títulos nobiliárquicos ou honoríficos da pessoa singular } \\
\text { ou da família. }\end{array}$ \\
\hline $\begin{array}{l}\text { 1. } 6 \text { Identificadores para } \\
\text { pessoas coletivas }\end{array}$ & $\begin{array}{l}\text { Preenchimento } \\
\text { OP }\end{array}$ & $\begin{array}{l}\text { Referente a pessoas coletivas, pelo que não se } \\
\text { enquadra no presente trabalho. }\end{array}$ \\
\hline \multicolumn{3}{|r|}{ 2. Zona da Descrição } \\
\hline $\begin{array}{l}\text { 2. } 1 \text { Datas de } \\
\text { existência/atividade }\end{array}$ & $\begin{array}{l}\text { Preenchimento } \\
\mathrm{O}\end{array}$ & $\begin{array}{l}\text { O objetivo deste elemento de informação é registar } \\
\text { as datas de existência/atividade da pessoa coletiva, da } \\
\text { pessoa singular ou da família. } \\
\text { Para as pessoas singulares incluir as datas, aproximadas } \\
\text { ou precisas, de nascimento, morte ou, quando estas } \\
\text { são desconhecidas, indicar as datas de atividade } \\
\text { (floruit). Quando são utilizados sistemas paralelos } \\
\text { de datação, podem ser registadas as equivalências, } \\
\text { segundo convenções ou regras apropriadas. } \\
\text { Formato utilizados para as datas extremas exatas: } \\
\text { AAAA-MM-DD-AAAA-MM-DD. }\end{array}$ \\
\hline
\end{tabular}




\begin{tabular}{|c|c|c|}
\hline 2. 2 História & $\begin{array}{l}\text { Preenchimento } \\
\text { OP }\end{array}$ & $\begin{array}{l}\text { O objetivo deste elemento de informação é registar } \\
\text { de uma história concisa da pessoa coletiva, da pessoa } \\
\text { singular ou da família. } \\
\text { O preenchimento deste elemento para as pessoas } \\
\text { singulares ou famílias aqui descritas foi feito } \\
\text { respeitando o princípio da não repetição de } \\
\text { informação. } \\
\text { Registar, de forma narrativa ou através de uma } \\
\text { cronologia, os principais eventos, atividades, } \\
\text { realizações e/ou funções da entidade descrita. Sempre } \\
\text { que possível, fornecer as datas como parte integrante } \\
\text { da descrição narrativa. Registar a história para as } \\
\text { pessoas singulares, incluindo informação sobre a vida } \\
\text { familiar (filiação, cônjuge, filhos e outros parentescos), } \\
\text { a escolaridade (estudos e formação obtida, respetivas } \\
\text { instituições, diplomas), a atividade social (participação } \\
\text { em açôes, eventos, atos cívicos, etc.) e profissional } \\
\text { (atividade, cargos), outros tipos de atividade (hobbies, } \\
\text { interesses) e outros aspetos relevantes para a } \\
\text { caracterização da pessoa (convicções religiosas ou } \\
\text { políticas, etc.). } \\
\text { Para as famílias, registar a história para as famílias } \\
\text { incluindo informação sobre a origem, evolução, } \\
\text { uniões familiares, apelidos (mudanças ou acréscimos } \\
\text { e respetivas datas), títulos de nobreza ou títulos } \\
\text { honoríficos (respetivas datas e diplomas de atribuição), } \\
\text { membros que se destacaram, atividades e funções } \\
\text { desempenhadas (contexto e respetivas datas) e } \\
\text { outros aspetos considerados relevantes para a sua } \\
\text { caracterização. }\end{array}$ \\
\hline 2. 3 Lugares & $\begin{array}{l}\text { Preenchimento } \\
\text { OP }\end{array}$ & $\begin{array}{l}\text { O objetivo deste elemento de informação é registar os } \\
\text { lugares onde a pessoa coletiva, a pessoa singular ou a } \\
\text { família estiveram sediadas, residiram, desenvolveram } \\
\text { as suas atividades. } \\
\text { Registar o nome do(s) lugar(es) e/ou jurisdição(ões) } \\
\text { predominantes, bem como a natureza e o período da } \\
\text { relação com a entidade. }\end{array}$ \\
\hline 2. 4 Estatuto legal & $\begin{array}{l}\text { Preenchimento } \\
\text { OP }\end{array}$ & $\begin{array}{l}\text { Referente a pessoas coletivas, pelo que não se } \\
\text { enquadra no presente trabalho. }\end{array}$ \\
\hline $\begin{array}{l}\text { 2. } 5 \text { Funções, ocupações, } \\
\text { atividades }\end{array}$ & $\begin{array}{l}\text { Preenchimento } \\
\text { OP }\end{array}$ & $\begin{array}{l}\text { O objetivo deste elemento de informação é indicar as } \\
\text { funções, ocupações e atividades desenvolvidas pela } \\
\text { pessoa coletiva, pela pessoa singular ou pela família. } \\
\text { Registar as funções, ocupações e atividades } \\
\text { desenvolvidas pela entidade descrita, em conjunto } \\
\text { com as respetivas datas, se aplicável. Se necessário, } \\
\text { descrever a natureza da função, ocupação ou } \\
\text { atividade. }\end{array}$ \\
\hline
\end{tabular}




\begin{tabular}{|c|c|c|}
\hline $\begin{array}{l}\text { 2. } 6 \text { Mandatos / Fontes } \\
\text { de autoridade }\end{array}$ & \begin{tabular}{|l|} 
Preenchimento \\
OP
\end{tabular} & $\begin{array}{l}\text { O objetivo deste elemento de informação é registar } \\
\text { as fontes de autoridade onde foram determinados } \\
\text { os poderes, funções, esfera de atividade da pessoa } \\
\text { coletiva, pessoa singular ou família. } \\
\\
\text { Para as pessoas singulares registar os textos ou } \\
\text { documentos legais de nomeação para cargos, funções } \\
\text { ou responsabilidades da pessoa singular; para as } \\
\text { famílias registar os textos ou documentos legais de } \\
\text { aquisição, concessão e doação de bens, direitos e } \\
\text { prerrogativas, de nomeação para cargos e funções } \\
\text { ou responsabilidades da família, seguindo o critério } \\
\text { cronológico. }\end{array}$ \\
\hline $\begin{array}{l}\text { 2. } 7 \text { Estruturas internas / } \\
\text { Genealogia }\end{array}$ & \begin{tabular}{|l|} 
Preenchimento \\
O114
\end{tabular} & $\begin{array}{l}\text { O objetivo deste elemento de informação é registar } \\
\text { as estruturas administrativas internas de uma pessoa } \\
\text { coletiva ou a genealogia de uma família. } \\
\text { Descrever a genealogia da família (através de uma } \\
\text { árvore genealógica, por exemplo) de forma a } \\
\text { evidenciar as relações entre os seus membros e as } \\
\text { datas respetivas. }\end{array}$ \\
\hline 2. 8 Contexto geral & \begin{tabular}{|l|} 
Preenchimento \\
OP
\end{tabular} & $\begin{array}{l}\text { O objetivo deste elemento de informação é registar } \\
\text { informação significativa sobre o contexto social, } \\
\text { económico, político, histórico, cultural ou outro, no } \\
\text { qual a pessoa coletiva, a pessoa singular ou a família } \\
\text { desenvolveram a sua atividade } 115 \text {. } \\
\text { Fornecer qualquer informação significativa sobre o } \\
\text { contexto social, cultural, económico, político e/ou } \\
\text { histórico no qual a entidade descrita desenvolveu a sua } \\
\text { atividade. }\end{array}$ \\
\hline \multicolumn{3}{|c|}{ 3. Zona das Relações } \\
\hline $\begin{array}{l}\text { 3. } 1 \text { Nome/ldentificador } \\
\text { da pessoa coletiva, da } \\
\text { pessoa singular ou da } \\
\text { família relacionadas }\end{array}$ & \begin{tabular}{|l|} 
Preenchimento \\
O116 $^{116}$
\end{tabular} & $\begin{array}{l}\text { O objetivo deste elemento de informação é registar } \\
\text { os nomes das entidades que, de algum modo, estão } \\
\text { relacionadas com a pessoa coletiva, a pessoa singular } \\
\text { ou a família descrita. Este registo é feito utilizando a } \\
\text { Forma autorizada do nome das entidades relacionadas } \\
\text { e/ou o Identificador do registo de autoridade das } \\
\text { referidas entidades relacionadas } 117 \text {. }\end{array}$ \\
\hline
\end{tabular}

114 Decidimos que este campo deveria, mesmo no registo mínimo, ser obrigatório, contendo elementos genealógicos e/ou de percurso individual.

115 Ib.: 250

116 Uma vez que se trata de arquivo de família, é muito importante o preenchimento deste campo, mesmo nos quesitos mínimos.

117 Ib.: 251-252. 


\begin{tabular}{|c|c|c|}
\hline 3. 2 Tipo de relação & $\begin{array}{l}\text { Preenchimento } \\
\mathrm{O}^{118}\end{array}$ & $\begin{array}{l}\text { O objetivo deste elemento de informação é registar o } \\
\text { tipo de relação existente entre a entidade descrita e a } \\
\text { pessoa coletiva, pessoa singular ou família relacionada. } \\
\text { Registar um tipo geral no qual se insira a relação } \\
\text { descrita, registar no elemento Regras e/ou convenções } \\
\text { qualquer esquema de classificação usado como fonte } \\
\text { dos termos do vocabulário controlado para descrever } \\
\text { a relação. Este campo pode ser descrito recorrendo a } \\
\text { quatro tipos de descritores: } \\
\text { - Hierárquica (por exemplo superior/ subordinado; } \\
\text { proprietário/propriedade). } \\
\text { Numa relação hierárquica uma entidade pode exercer } \\
\text { alguma autoridade e controlo sobre as atividades de } \\
\text { um certo número de outras pessoas coletivas, pessoas } \\
\text { singulares ou famílias. Uma entidade pode também } \\
\text { estar subordinada a várias outras pessoas coletivas, } \\
\text { pessoas singulares ou famílias, tal como, por exemplo, } \\
\text { um comité associado ou uma organização cuja tutela } \\
\text { mudou ao longo do tempo. } \\
\text { - Cronológica (por exemplo predecessor/ sucessor) } \\
\text { Numa relação temporal uma entidade pode suceder a } \\
\text { várias outras pessoas coletivas, pessoas singulares ou } \\
\text { famílias no exercício de algumas funções e atividades. } \\
\text { Por outro lado pode ser sucedida por várias pessoas } \\
\text { coletivas, pessoas singulares ou famílias. } \\
\text { - Familiar } \\
\text { Numa família uma pessoa pode ter um largo círculo } \\
\text { de relações com outros membros da família e com } \\
\text { a família enquanto entidade. Quando a estrutura } \\
\text { genealógica da família é complexa, pode ser apropriada } \\
\text { a criação de registos de autoridade separados para } \\
\text { cada membro e a sua ligação ao(s) pai(s), esposa(s) } \\
\text { ou filho(s). Em alternativa esta informação pode ser } \\
\text { registada no elemento Estruturas internas/Genealogia } \\
\text { - Associativa } \\
\text { Uma relação associativa é uma categoria geral para } \\
\text { relações que se não incluem em nenhuma das acima } \\
\text { referidas (por exemplo: Fornecedor/ cliente, membro, } \\
\text { parte/todo, sócio). } \\
\text { No preenchimento deste elemento de informação foi } \\
\text { utilizada a linguagem controlada estabelecida pelas } \\
\text { ODA119. }\end{array}$ \\
\hline
\end{tabular}

118 Uma vez que se trata de arquivo de família, é muito importante o preenchimento deste campo, mesmo nos quesitos mínimos..

119 Ib.: 253-254. 


\begin{tabular}{|c|c|c|}
\hline $\begin{array}{l}\text { 3. } 3 \text { Descrição da } \\
\text { relação }\end{array}$ & $\begin{array}{l}\text { Preenchimento } \\
\text { OP }\end{array}$ & $\begin{array}{l}\text { O objetivo deste elemento de informação é registar } \\
\text { a natureza específica da relação existente entre a } \\
\text { entidade descrita e a pessoa coletiva, pessoa singular } \\
\text { ou família relacionada. } \\
\text { Registar uma descrição precisa da natureza da relação } \\
\text { entre a entidade descrita no registo de autoridade } \\
\text { e a outra entidade relacionada, por exemplo: } \\
\text { subordinante, subordinada, proprietário, predecessor, } \\
\text { marido, mulher, filho, primo, professor de, aluno de, } \\
\text { colega profissional. Registar no elemento Regras e/ou } \\
\text { convenções qualquer esquema de classificação usado } \\
\text { como fonte dos termos do vocabulário controlado } \\
\text { para descrever a relação. Também pode ser dada, } \\
\text { neste elemento, uma descrição narrativa da história e/ } \\
\text { ou natureza da relação. } \\
\text { No preenchimento deste elemento de informação foi } \\
\text { utilizada a linguagem controlada descrita nas ODA } 120\end{array}$ \\
\hline 3. 4 Datas da relação & $\begin{array}{l}\text { Preenchimento } \\
\mathrm{O}^{121}\end{array}$ & $\begin{array}{l}\text { O objetivo deste elemento de informação é indicar } \\
\text { as datas de duração da relação com outras pessoas } \\
\text { coletivas, pessoas singulares ou famílias. } \\
\text { Para o caso das pessoas aqui descritas e das suas } \\
\text { relações, foi registada a data em que ocorreu } \\
\text { a relação, geralmente casamento e ou data de } \\
\text { nascimento e morte das entidades relacionadas. } \\
\text { Formato utilizados para as datas extremas exatas: } \\
\text { AAAA-MM-DD-AAAA-MM-DD. }\end{array}$ \\
\hline \multicolumn{3}{|c|}{ 4. Zona do Controlo } \\
\hline $\begin{array}{l}\text { 4. } 1 \text { Identificador do } \\
\text { registo } \\
\text { de autoridade }\end{array}$ & $\begin{array}{l}\text { Preenchimento } \\
\mathrm{O}\end{array}$ & $\begin{array}{l}\text { O objetivo deste elemento de informação é criar um } \\
\text { identificador unívoco para o registo de autoridade } \\
\text { arquivística. } \\
\text { Registar um identificador unívoco do registo de } \\
\text { autoridade de acordo com convenções locais e/ou } \\
\text { nacionais. Se o registo de autoridade se destinar a } \\
\text { uma utilização internacional, registar o código do país } \\
\text { responsável pela sua criação, de acordo com a última } \\
\text { versão da ISO } 3166 \text { Codes for the representation of } \\
\text { names of countries } 122 \text {. }\end{array}$ \\
\hline
\end{tabular}




\begin{tabular}{|c|c|c|}
\hline $\begin{array}{l}\text { 4. } 2 \text { Identificadores da } \\
\text { instituição }\end{array}$ & $\begin{array}{l}\text { Preenchimento } \\
\text { OP }\end{array}$ & $\begin{array}{l}\text { O objetivo deste elemento de informação é a } \\
\text { identificação dos serviços responsáveis pela criação do } \\
\text { registo de autoridade. } \\
\text { Registar, de forma completa, a forma autorizada do(s) } \\
\text { nome(s) do(s) serviço(s) responsável(eis) pela criação } \\
\text { do registo de autoridade ou, em alternativa, registar } \\
\text { o código do serviço, segundo o código nacional ou } \\
\text { internacional. Incluir a referência a quaisquer sistemas } \\
\text { de identificação usados para as instituições (por } \\
\text { exemplo ISO 15511). }\end{array}$ \\
\hline $\begin{array}{l}\text { 4. } 3 \text { Regras e/ou } \\
\text { convenções }\end{array}$ & $\begin{array}{l}\text { Preenchimento } \\
\mathrm{O}^{123}\end{array}$ & $\begin{array}{l}\text { O objetivo deste elemento de informação é a } \\
\text { identificação das convenções, normas ou regras, } \\
\text { nacionais e internacionais, aplicadas na criação do } \\
\text { respetivo registo de autoridade arquivística. } \\
\text { Registar os nomes e, se necessário as edições ou datas } \\
\text { de publicação das convenções ou regras aplicadas. } \\
\text { Especificar, separadamente, que regras foram aplicadas } \\
\text { para a construção da forma autorizada do nome. } \\
\text { Incluir a referência a qualquer(isquer) sistema(s) de } \\
\text { datação utilizado(s) para identificar as datas no registo } \\
\text { de autoridade (por exemplo ISO 8601). } \\
\text { As orientações e normas devem ser registadas segundo } \\
\text { as normas de citação estabelecidas pela NP-405. }\end{array}$ \\
\hline 4. 4 Estatuto & $\begin{array}{l}\text { Preenchimento } \\
\text { OP }\end{array}$ & $\begin{array}{l}\text { O objetivo deste elemento de informação é indicar } \\
\text { o estado de elaboração do registo de autoridade } \\
\text { arquivística, para que o utilizador possa perceber o seu } \\
\text { estatuto corrente }{ }^{124} \text {. } \\
\text { Os registos de autoridade criados no âmbito deste } \\
\text { trabalho foram todos considerados como preliminares. }\end{array}$ \\
\hline 4. 5 Nível de detalhe & $\begin{array}{l}\text { Preenchimento } \\
\text { OP }\end{array}$ & $\begin{array}{l}\text { O objetivo deste elemento de informação é indicar } \\
\text { qual o nível de detalhe do registo de autoridade } \\
\text { arquivística. } \\
\text { Tal nível é determinado pelos elementos de informação } \\
\text { que são preenchidos na criação do registo } 125 \text {. } \\
\text { Os registos criados no âmbito deste trabalho foram } \\
\text { considerados "parcial". }\end{array}$ \\
\hline $\begin{array}{l}\text { 4. } 6 \text { Datas de criação, } \\
\text { revisão } \\
\text { ou eliminação }\end{array}$ & $\begin{array}{l}\text { Preenchimento } \\
0^{126}\end{array}$ & $\begin{array}{l}\text { O objetivo deste elemento de informação é indicar as } \\
\text { datas de criação, revisão, modificação ou eliminação } \\
\text { do registo de autoridade arquivística. }\end{array}$ \\
\hline
\end{tabular}

123 Uma vez que se trata de arquivo de família, é muito importante o preenchimento deste campo, mesmo nos quesitos mínimos.

$124 \quad$ Ib.: 267.

125 Ib.: 268.

126 Uma vez que se trata de arquivo de família, é muito importante o preenchimento deste campo, mesmo nos quesitos mínimos e serve para controlarmos o andamento do trabalho. 


\begin{tabular}{|c|c|c|}
\hline 4. 7 Línguas e escritas & $\begin{array}{l}\text { Preenchimento } \\
\text { OP }\end{array}$ & $\begin{array}{l}\text { O objetivo deste elemento de informação é indicar } \\
\text { o idioma e a escrita utilizados para criar o registo de } \\
\text { autoridade arquivística. } \\
\text { No caso dos registos criados no âmbito deste trabalho, } \\
\text { o idioma foi o Português e a escrita Latina } 127 \text {. }\end{array}$ \\
\hline 4. 8 Fontes & $\begin{array}{l}\text { Preenchimento } \\
\mathrm{O}\end{array}$ & $\begin{array}{l}\text { O objetivo deste elemento de informação é referir as } \\
\text { fontes utilizadas na descrição e na criação do registo } \\
\text { de autoridade arquivística } 128 \text {. }\end{array}$ \\
\hline $\begin{array}{l}\text { 4. } 9 \text { Notas de } \\
\text { manutenção }\end{array}$ & $\begin{array}{l}\text { Preenchimento } \\
0^{129}\end{array}$ & $\begin{array}{l}\text { O objetivo das Notas de manutenção é fornecer } \\
\text { informação acerca da criação e manutenção do registo } \\
\text { de autoridade arquivística. } \\
\text { O dado mais pertinente a registar neste elemento é } \\
\text { o nome da pessoa responsável pela elaboração do } \\
\text { registo } 130 \text {. }\end{array}$ \\
\hline \multicolumn{3}{|c|}{$\begin{array}{l}\text { 5. Relações das pessoas coletivas, pessoas singulares e famílias com a documentação } \\
\text { de arquivo e outros recursos } 131\end{array}$} \\
\hline $\begin{array}{l}\text { 5. } 1 \text { Identificadores e } \\
\text { títulos do recurso } \\
\text { relacionado }\end{array}$ & $\begin{array}{l}\text { Preenchimento } \\
\mathrm{O}^{132}\end{array}$ & $\begin{array}{l}\text { O objetivo deste elemento de informação é identificar } \\
\text { e/ou estabelecer a ligação, de forma unívoca, } \\
\text { entre o registo de autoridade criado e os recursos } \\
\text { relacionados. } \\
\text { Estes recursos podem ser recursos arquivísticos (fundos } \\
\text { documentais produzidos pela entidade descrita, por } \\
\text { exemplo), ou outro tipo de recursos, como recursos } \\
\text { bibliográficos, audiovisuais, fotográficos, sonoros, } \\
\text { arqueológicos, artísticos, bens móveis ou imóveis. Os } \\
\text { recursos relacionados mais comuns são os arquivísticos. } \\
\text { Para as pessoas singulares e famílias aqui descritas } \\
\text { foi estabelecida a relação entre estas e os respetivos } \\
\text { fundos documentais. } \\
\text { Foi sempre registada a designação controlada dos } \\
\text { recursos relacionados, seguida do respetivo identificador } \\
\text { unívoco, tendo como fontes de informação os } \\
\text { respectivos instrumentos de descrição } 133 \text {. }\end{array}$ \\
\hline
\end{tabular}

\section{Ib.: 270 \\ 128 Ib : 271 .}

129 Uma vez que se trata de arquivo de família, é muito importante o preenchimento deste campo, mesmo nos quesitos mínimos.

130 Ib.: 272.

131 O preenchimento dos elementos de informação relativos às relações das pessoas coletivas, pessoas singulares e famílias com a documentação de arquivo é obrigatório. Já o registo das relações das pessoas coletivas, pessoas singulares e famílias com outros recursos é opcional (ib.: 214).

132 Uma vez que se trata de arquivo de família, é muito importante o preenchimento deste campo, mesmo nos quesitos mínimos.

133 Ib.: 273-275. 


\begin{tabular}{|l|l|l|}
\hline $\begin{array}{l}\text { 5.2 Tipo do recurso } \\
\text { relacionado }\end{array}$ & $\begin{array}{l}\text { Preenchimento } \\
\text { O }\end{array}$ & $\begin{array}{l}\text { O objetivo deste elemento de informação é identificar } \\
\text { o tipo dos recursos relacionados que foram registados } \\
\text { no elemento anterior 134. }\end{array}$ \\
\hline 5.3 Natureza da relação & $\begin{array}{l}\text { Preenchimento } \\
\text { O }\end{array}$ & $\begin{array}{l}\text { O objetivo deste elemento de informação é identificar } \\
\text { a natureza das relações entre o registo de autoridade } \\
\text { criado e os recursos relacionados. } \\
\text { Para o caso das pessoas singulares e famílias aqui } \\
\text { descritas, a natureza da relação com os recursos } \\
\text { arquivísticos identificados foi a de produtor 135. }\end{array}$ \\
\hline $\begin{array}{l}\text { 5.4 Datas do recurso } \\
\text { relacionado }\end{array}$ & $\begin{array}{l}\text { Preenchimento } \\
\text { O objetivo deste elemento de informação é identificar } \\
\text { as datas dos recursos relacionados e/ou as datas } \\
\text { da relação entre o registo de autoridade criado e o } \\
\text { recurso relacionado, indicando o seu significado. }\end{array}$ \\
\hline
\end{tabular}

\footnotetext{
134 Ib.: 276-277.

135 Ib.: 278-279
} 